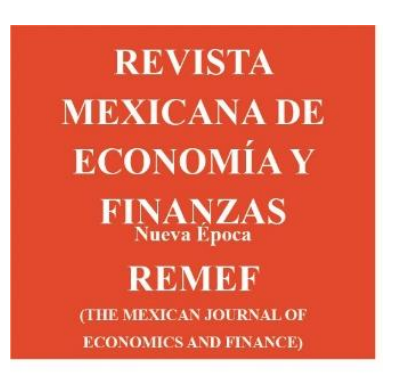

Revista Mexicana de Economía y Finanzas, Nueva Época

Volumen 16 TNEA, September 2021, pp. 1-27, e539

TOPICS IN BANKING AND FINANCIAL INSTITUTIONS

Guest Editor: Dr. Adrián Rossignolo

DOI: https://doi.org/10.21919/remef.v16i0.539

(Received: August 20, 2020, Accepted: November 23, 2020.

Published: August 31, 2021)

\title{
The New Standardised Approach as a Credible Fallback
}

\author{
Adrián F. Rossignolo ${ }^{1}$ - University of Leicester, United Kingdom
}

The paper intends to measure the effect of Basel IV's revamped Standardised Approach (SA) as a credible fallback to the Internal Models Approach. Using equity portfolios in the UK and US, the analysis reveals somewhat high Minimum Capital Requirements (MCR), conferring these figures an extra conservative nature. This, In turn, would generate disincentives to develop precise Internal Models stifling financial innovation, which could be remedied introducing slight changes in SA's specification. A simulation analysis shows that, varying the fixed components of the formula alongside the introduction of calibration parameters, the output floor could be tailored to suit the needs of the local regulators using a stressed yardstick like the Loss Coverage Ratio, although every precaution must be taken in this regard. The present study ranks amongst the first to quantify the level of the output floor outside the BCBS and evaluate it against a crisis of considerable magnitude, finding that the current configuration delivers relatively excessive MCRs and, furthermore, providing alternative solutions that could enable the constitution of adequate -albeit not disproportionate- capital coverage.

JEL Classification: C53, F37, F38, G01, G18, G28.

Keywords: Basel Committee, Capital Requirements, Standardised Approach, Risk Weights, Correlation Parameters.

\section{El nuevo enfoque estandarizado como alternativa creíble}

El artículo intenta mensurar el efecto del Enfoque Estandarizado (SA) modificado de Basilea IV como un soporte creíble para el enfoque de Modelos Internos (IMA). Empleando portafolios accionarios de UK y US, el análisis revela Capitales Mínimos Regulatorios (MCR) algo elevados, confiriendo a dichos valores una naturaleza extra-conservadora. Ello, a su vez, generaría desincentivos para el desarrollo de Modelos Internos precisos ahogando la innovación financiera, hecho que podría remediarse introduciendo cambios mínimos en la especificación de SA. Un análisis de simulación muestra que la variación de los componentes fijos de la fórmula conjuntamente con la introducción de parámetros de calibración permiten adaptar los MCR a las necesidades de los reguladores locales utilizando un indicador estresado como el Ratio de Cobertura de Pérdidas, siempre bajo extrema precaución. Este estudio se sitúa entre los primeros -excluido el BCBS- al momento de cuantificar el nivel de capital mínimo y evaluarlo en función de una crisis de magnitud considerable hallando que la configuración actual entrega MCR relativamente excesivos; adicionalmente, proporciona soluciones alternativas que permitirían la constitución de coberturas de capital adecuadas - mas no desproporcionadas-.

Clasificación JEL: C53, F37, F38, G01, G18, G28.

Palabras clave: Comité de Basilea, Requisitos de capital, Enfoque estandarizado, Pesos de riesgo, Parámetros de correlación.

1 Corresponding author. Dirección: Avenida del Libertador 774, Piso 1, Departamento “0”, C1009ABU, Buenos Aires, Argentina. Teléfono: +54-9-11-4038-19005. Correo electrónico: afr6@leicester.ac.uk

* No source of funding for research development 


\section{Introduction}

Following the collapse of the banking system as a result of the subprime crisis of 2007-2008, the Basel Committee on Banking Supervision (henceforth BCBS) decided to radically modify the Basel II Capital Accord (BCBS, 2006), in force at that time. With hindsight, the action may be regarded as a smart and proper move given the fact that the existing order contained many directives that allowed banks to constitute a reduced capital base, thus leaving them vulnerable to huge market slumps as it unfortunately occurred. In this sense, the provisions contained in the Basel 2.5 document (BCBS, 2011b) that eventually evolved into Basel III Capital Accord (BCBS, 2009), demanded -among many additional aspects-that banks should increase the regulatory capital derived from the Internal Models Approach (IMA) by adding a stressed Value-at-Risk (sVaR) component to the Basel II IMA configuration. Even though it represented a healthy substantial raise of the capital base, the simple avenue materialised in the Standardised Approach (SA) still provides financial institutions an easy escape route from the more intricate IMA, furthermore offering the dubious advantage of building up a significantly lower equity base.

The aforementioned duality (IMA-SA), which origins could be traced back to Basel II, embodied an anomaly that grew in importance in Basel III (as highlighted in Rossignolo, Fethi and Shaban, 2013), therefore fostering the surge of disincentives to adopt more accurate models belonging to the IMA. Moreover, both Basel II and Basel III strengthened the bias against precise techniques, avoiding enhancing the penalties envisaged for inaccuracy and hence gifting lifelines to unsound models like Historical Simulation or those based on the Normal distribution.

However, with the implementation of Basel III still underway, the BCBS acknowledged many weaknesses in the risk measurement process, both in terms of the models-based approach IMA and the SA as well (BCBS, 2011a). In the former case, many of the shortcomings that had already been pointed out in the literature (e.g., Manganelli and Engle, 2001; Finger, 2009; Danielsson, 2002; Danielsson and Zigrand 2006 and Rossignolo, Fethi and Shaban, 2013) referred to VaR's failures: lack of coherence as a risk metric, procyclicality and deficient information about the profile of losses beyond the threshold, just to cite a few ones. However, most relevantly, the academic literature questioned VaR as a risk metric and suggested the adoption of other metrics compliant with the axioms of coherence like Expected Shortfall (ES), in addition capable of resolving the issues posed by VaR snags. On the other hand, the SA revealed itself as insensitive to risk and, in many circumstances, the flat rate coupled with some supplements delivered excessive amounts of capital requirements as compared with the IMA, although the academia has not devoted comprehensive attention to it.

On those grounds, the BCBS took due notice and embarked on a massive overhaul of the present market risk framework, proposing a radical alteration of the current structure. The modifications range from the replacement of VaR for ES (formerly advocated by Artzner, Delbaen, Eber and Heath, 1999 and Acerbi and Tasche, 2002) and its associated issues like the validation process to a complete revamp of the SA with a view to addressing its inherent failures. Furthermore, the renovation includes the enactment of a new relationship between the SA and the IMA by means of which the former is to act as a "credible fall-back" to the latter. These new set of measures and directives have been compiled in many Consultative Papers (BCBS, 2012, 2013, 2014) and a final one 
stating the Standards (BCBS, 2016), which, taken together, convey a clear and definite idea about the course followed for the next Basel IV Capital Accord.

Arguably one of the most relevant changes of the so-called Basel IV resides in the refurbished $\mathrm{SA}$, rooting in the insertion of several specific parameters like $R W$ (Risk Weights) and the set of correlation parameters within assets of the same risk bucket $(\rho)$ and between risk buckets $(\gamma)$. These bunch of fixed variables convey a mysterious air to the approach, hence the paper intends to shed light on the effect that each one of those provokes on the ultimate result, i.e., the Minimum Capital Requirements (MCR). Stemming from the aforementioned issues, the article attempts to tackle the following points regarding the implementation of SA in major stock markets: firstly, it reviews the proposed change in Basel III regulations contained in Basel IV; secondly, it analyses the impact that each factor exerts on the MCR compared with the standardised expression issued by the BCBS, and, thirdly, it evaluates the implications of the adoption of the SA and suggests suitable alternative remedies that may help to prevent somewhat inadequate results.

The main contributions of the article arise from the fact that the current work ranks amongst the very first attempts to quantify or measure the full impact of the revamped SA on the MCR altering the foundations of the appraisal, pinpoint the potential inconsistencies that may appear in the implementation process and put forward straightforward courses of action in order to mitigate them.

The paper is structured as follows: Section 2 outlines a revision of the literature related to Basel IV, with special emphasis on the lack of quantitative studies regarding the SA; Section 3 stages the innovations that Basel IV introduces with reference to the SA; Section 4 details the Methodology carried out throughout the investigation; Section 5 presents the Results obtained and, finally, Section 6 states the Conclusions of the whole research.

\section{Literature review}

The ripples of the 2007-2008 financial crisis seem to linger to the present time. In effect, after detecting the problems of Basel II, the BCBS enacted Basel III, which contained a host of changes, basically through the adoption of the stressed VaR and further capital cushions like the Capital Conservation Buffer and the Countercyclical Capital Buffer, in addition to higher capital requirements for Systemically Important Financial Institutions (SIFIs) (BCBS, 2009). However, those variations were applied to the IMA, and the capital floors determined by the SA remained unaffected.

The literature has hitherto somewhat overlooked the SA and mainly concentrated on the whole spectrum of issues connected with the IMA, which range from the methodology to the specific behaviour of the models involved. In this sense, some regulators questioned (and blamed) the use of VaR (FSA, 2009; BCBS, 2013) and, consequently, some authors advocated its substitution for ES instead (Artzner, Delbaen, Eber and Heath, 1999; Acerbi and Tasche, 2002; McNeil, Frey and Embrechts, 2005). There was, then, an academic consensus about the need to switch from VaR to ES, to which the BCBS (2012) paid heed and acted consequently. Once this matter has in principle been settled, the question about which representation to apply seems far from being settled even though it has been extensively discussed. In that sense, is clear that glitches in Historical Simulation turns it unviable (Manganelli and Engle, 2001; Finger, 2006), while the application of representations based on the dynamic nature of volatility -appears well beyond doubt, either in the shape of Conditional Volatility (Christoffersen, 2003; Alexander, 2008) or Filtered Historical Simulation models (Barone- 
Adesi, Bourgoin and Giannakopoulos, 1998, and Boudoukh, Richardson and Whitelaw, 1998). Furthermore, even though volatility is regarded as a conditional phenomenon (Engle, 1982; Bollerslev, 1986; Nelson, 1991), the question of the distribution of the standardised residuals is not to be neglected. Accordingly, while the conventional (and most widespread) recipe involves the use of the Normal distribution (JP Morgan and Reuters, 1996; Van den Goorbergh and Vlaar, 1999) stress that the Student-t distribution improves the precision when modelling fat tails, which are eventually the most pressing concern for regulators. However, when the so-called 'black swans' (Taleb, 2007) strike markets, application of the Extreme Value Theory (EVT) is almost unrivalled (da Silva and de Melo Mendes, 2003), Reiss and Thomas, 2007), to the extent that Rossignolo, Fethi and Shaban, 2013, show that its usage could have averted or at least ameliorated the 2008 financial crises if enforced even in Basel II configuration.

The aforementioned references are only a token of the fact that the financial community devoted its attention to the IMA instead of the SA, which may be justified in part because of the limited approach characteristic of the flat rate of the SA in Basel I, II and III. Rossignolo, Fethi and Shaban, 2013 , ventured to suggest that that scheme did not provide sufficient coverage in the event of a major market crisis and perhaps on those grounds, the BCBS decided to overhaul the full procedure. In that vein, Magnus, Duvillet-Margerit and Mesnard, 2017, welcomed the more granular and risk-sensitive appraisal taken by the BCBS in view of the problems encountered in the European Union, notwithstanding which the remaining literature comes from specialised consultancy firms with little or few quantitative considerations. In effect, Deloitte UK, 2015, pointed out that the new sensitivitybased methodology resembled a VaR simulation while KPMG, 2016, highlighted that the enforcement of Basel IV will undoubtedly bring about higher capital costs, as the SA shall set higher capital floors to constrain the extent to which banks can use their internal models to drive their capital requirements below those of SA and Schneider S., Schröck, Koch and Schneider, R,., 2017, focused on the reduction of the profitability and the development of a consistent set of metrics for efficient capital allocation purposes. Finally, Jackson, 2016, affirms that the new SA appears difficult to implement in view of its high prescriptiveness, the requirement of enhancements to current market data and the development of new internal processes to address the revised boundary between trading and banking books.

The current study intends to fill the observed gap in the literature, ascertaining the impact of the introduction of the overhauled SA on the MCR, simultaneously proposing an alternative (and more transparent) procedure to compute the fixed Risk Weights and correlation parameters which could eventually tailor the capital requirements to the supervisors' specific needs, therefore limiting largeness and avoiding the deterioration of the capital return metrics.

\section{Basel IV New Standardised Approach}

The BCBS, 2016, has performed a thorough revision of the market risk provisions with a view to enacting new capital requirements for that kind of risk which contains five stumbling blocks: a) revised Internal Models-Approach; b) redesigned Standardised Approach; c) shift from Value-at-Risk to an expected Expected Shortfall strained metric of risk; d) inclusion of the risk of market illiquidity 
and e) redefined boundary between trading and banking books. In view of the scope of the study, only item b) will be analysed.

The modification of the SA constitutes arguably one of the most radical innovations of Basel IV. Riding on the known concepts that the SA should provide a method to compute the capital base for those banks not in need of sophisticated risk models and, furthermore, act as a fall-back to inadequate internal models, the appraisal appears hugely revamped following a "partial risk approach" resembling the classic portfolio theory (Markowitz, 1952), although with pre-specified risk weights and correlation parameters. In effect, instruments with similar risk patterns are grouped into risk buckets for which the BCBS affixes predetermined risk weights and, moreover, the hedging and diversification effects are seized by means of preset correlation factors.

Specifically, the capital charge for equity risk is obtained after the ensuing steps:

a) Step 1: allocation of net notional positions ${ }^{2}$ in the respective risk bucket according to a criterion that takes into account the size, region and sector of the company (Table 1). The boundary between "large" and "small" companies is established in a market capitalisation of USD 2 billion, and developed markets encompass the following ones: United States, Canada, the Eurozone, United Kingdom, Norway, Sweden, Denmark, Switzerland, Japan, Australia and New Zealand. Additionally, each bucket bears its own risk weight (Table 2). and the "Residual Bucket" gathers all companies that may not be allocated to buckets 1 to 10 because of data unavailability.

b) Step 2: application of the formula that acknowledges hedging and diversification within each risk bucket. Hence, for notional positions 1 to $n$ :

$$
K_{b}=\sqrt{\sum_{i=1}^{n} R W_{i}^{2} M V_{i}^{2}+\sum_{i=1}^{n} \sum_{j>i}^{n} \rho_{i j} R W_{i} M V_{i} R W_{j} M V_{j}}
$$

where $R W_{i}, M V_{i}$ and $\rho_{i j}$ represent the risk weight assigned to position $i$, the value of the notional position $i$ and the correlation parameter between positions $i$ and $j$ respectively. $\rho_{i j}$ is established differently in accordance with the equity exposures bearing identical or opposite signs $^{3}$ (Table 2).

c) Step 3: explicit acknowledgment of the hedging and diversification across risk buckets. This last stage of the process allows the obtention of the Equity Risk Capital (ERC) by means of the aggregation of the risk positions for each individual risk bucket. Thus (3.2),

$$
\text { Equity Risk Capital }(E R C)=\sqrt{\sum_{i=1}^{B} K_{b}^{2}+\sum_{b=1}^{B} \sum_{c>b} \gamma_{b c} S_{b} S_{c}}+K_{\text {Residual }}
$$

where:

$\mathrm{K}_{\mathrm{b}} \quad$ : capital requirement determined in (3.1)

$\mathrm{K}_{\text {Residual }}$ : capital requirement due to the residual bucket

\footnotetext{
${ }^{2}$ The BCBS allows offsetting long and short positions on the same equity name, thus working with the net exposure.
}

${ }^{3}$ Identical sign refers to coincident long or short positions, whereas opposite sign denotes long and short exposures. 
$\mathrm{S}_{\mathrm{b}}$

$\gamma_{\mathrm{bc}}$
$: \sum_{i \in b} R W_{i} M V_{i}$

: correlation parameter between buckets $b$ and $c$, derived from the correlation matrix in Table 3.

Noticeably, even though firms may be allowed to develop their own internal models, they must comply with the obligation to calculate the MCR using the Standardised avenue, in practice meaning that all institutions are required to calculate it.

Table 1. BCBS's companies classification criteria

\begin{tabular}{|c|l|l|l|c|c|}
\hline $\begin{array}{c}\text { Bucket } \\
\text { No. }\end{array}$ & Size & Region & \multicolumn{1}{|c|}{ Sector } & $\begin{array}{c}\text { Risk } \\
\text { Weight }\end{array}$ \\
\hline 1 & Large & Emerging & $\begin{array}{l}\text { Consumer goods and services, transportation and storage, } \\
\text { administrative and support service activities, healthcare, } \\
\text { utilities }\end{array}$ & $55 \%$ \\
\hline 2 & Large & Emerging & Telecommunications, industrials & $60 \%$ \\
\hline 3 & Large & Emerging & $\begin{array}{l}\text { Basic materials, energy, agriculture, manufacturing, mining } \\
\text { and quarrying }\end{array}$ & $45 \%$ \\
\hline 4 & Large & Emerging & $\begin{array}{l}\text { Financials including government-backed financials, real } \\
\text { estate activities, technology }\end{array}$ & $55 \%$ \\
\hline 5 & Large & Developed & $\begin{array}{l}\text { Consumer goods and services, transportation and storage, } \\
\text { administrative and support service activities, healthcare, } \\
\text { utilities }\end{array}$ & $30 \%$ \\
\hline 6 & Large & Developed & Telecommunications, industrials & $35 \%$ \\
\hline 7 & Large & Developed & $\begin{array}{l}\text { Basic materials, energy, agriculture, manufacturing, mining } \\
\text { and quarrying }\end{array}$ & $40 \%$ \\
\hline 8 & Large & Developed & $\begin{array}{l}\text { Financials including government-backed financials, real } \\
\text { estate activities, technology }\end{array}$ & $50 \%$ \\
\hline 10 & Small & Emerging & All sectors described under bucket numbers 1, 2, 3 and 4 & $70 \%$ \\
\hline Residual & & Developed & $\begin{array}{l}\text { All sectors described under bucket numbers 5, 6, 7 and } 8 \\
\text { All other sectors }\end{array}$ & $50 \%$ \\
\hline
\end{tabular}

Source: Own elaboration

Table 2. Correlation coefficient $\rho$ within buckets

\begin{tabular}{|c|c|c|}
\hline Bucket No. & Same sign & Opposite sign \\
\hline 1 & $15 \%$ & $10 \%$ \\
\hline 2 & $15 \%$ & $15 \%$ \\
\hline 3 & $15 \%$ & $15 \%$ \\
\hline 4 & $15 \%$ & $20 \%$ \\
\hline 5 & $25 \%$ & $10 \%$ \\
\hline 6 & $25 \%$ & $15 \%$ \\
\hline 7 & $25 \%$ & $20 \%$ \\
\hline 8 & $25 \%$ & $20 \%$ \\
\hline 9 & $7.50 \%$ & $5 \%$ \\
\hline 10 & $12.50 \%$ & $10 \%$ \\
\hline
\end{tabular}

Source: Own elaboration 
Table 3. Correlation coefficient $\gamma$ between buckets

\begin{tabular}{|c|c|c|c|c|c|c|c|c|c|c|}
\hline Bucket & $\mathbf{1}$ & $\mathbf{2}$ & $\mathbf{3}$ & $\mathbf{4}$ & $\mathbf{5}$ & $\mathbf{6}$ & $\mathbf{7}$ & $\mathbf{8}$ & $\mathbf{9}$ & $\mathbf{1 0}$ \\
\hline $\mathbf{1}$ & $100 \%$ & & & & & & & & & \\
\hline $\mathbf{2}$ & $15 \%$ & $100 \%$ & & & & & & & & \\
\hline $\mathbf{3}$ & $15 \%$ & $15 \%$ & $100 \%$ & & & & & & & \\
\hline $\mathbf{4}$ & $15 \%$ & $15 \%$ & $15 \%$ & $100 \%$ & & & & & & \\
\hline $\mathbf{5}$ & $15 \%$ & $15 \%$ & $15 \%$ & $15 \%$ & $100 \%$ & & & & & \\
\hline $\mathbf{6}$ & $15 \%$ & $15 \%$ & $15 \%$ & $15 \%$ & $15 \%$ & $100 \%$ & & & & \\
\hline $\mathbf{7}$ & $15 \%$ & $15 \%$ & $15 \%$ & $15 \%$ & $15 \%$ & $15 \%$ & $100 \%$ & & & \\
\hline $\mathbf{8}$ & $15 \%$ & $15 \%$ & $15 \%$ & $15 \%$ & $15 \%$ & $15 \%$ & $15 \%$ & $100 \%$ & & \\
\hline $\mathbf{9}$ & $15 \%$ & $15 \%$ & $15 \%$ & $15 \%$ & $15 \%$ & $15 \%$ & $15 \%$ & $15 \%$ & $100 \%$ & \\
\hline $\mathbf{1 0}$ & $15 \%$ & $15 \%$ & $15 \%$ & $15 \%$ & $15 \%$ & $15 \%$ & $15 \%$ & $15 \%$ & $15 \%$ & $100 \%$ \\
\hline
\end{tabular}

\section{Methodology}

The present study was carried out on two of the three major stock exchanges of the world in terms of market capitalisation (World Federation of Exchanges, 2015): New York Stock Exchange (NYSE) and London Stock Exchange (LSE). In view of the degree of detail observed in the regulatory digest, it is relevant to state that the article will develop employing spot equity prices, in a bid to analyse the effect of the mandates avoiding potential distortions arising from the use of derivatives.

For the two exchanges, each stock listed on the respective blue chip index -Dow Jones Industrial Average (DJIA) in the former and FTSE100 (FTSE) in the latter- was classified according to the risk buckets (categories) 5-84 envisaged by BCBS, 2016.

As it may be observed, the BCBS establishes that the Risk Weight is fixed for each bucket, hence not allowing banks under SA to change it, and only defining them as equivalent to a standalone capital requirement (BCBS, 2016). Therefore, the article intends to ascertain the accuracy of the values provided in Table 1 computing the RW for buckets 5-8 both for DJIA and FTSE effectively as capital requirements applying an IMA under Basel IV mandate with different specifications on the respective bucket. For that purpose, it previously calculated a time series corresponding to each bucket using the Paasche methodology, much in the same fashion as the FTSE group utilises to calculate the FTSE100 index (FTSE, 2015):

$$
I_{t}^{B}=I_{t-1}^{B} \frac{\sum_{i=1}^{n} P_{i ; t} Q_{i ; t}}{\sum_{i=1}^{n} P_{i ; t-1} Q_{i ; t}}
$$

where:

$\mathrm{I}_{\mathrm{t}^{\mathrm{B}}}^{\mathrm{B}} \quad$ : Paasche Index for bucket $\mathrm{B}$ on day $t$

$\mathrm{P}_{\mathrm{i} ; \mathrm{t}} \quad$ : price at start of day $t$ for constituent $I$ after adjustments for corporate action or event

\footnotetext{
${ }^{4}$ BCBS, 2016, stipulated a framework of 10 buckets, where the first four and the ninth correspond to Emerging markets and fifth to eight and tenth belong to Developed ones. Risk buckets nine and ten denote 'Residual' buckets, designed for those companies which activity cannot be allocated in any of the aforementioned groups.
} 

$\mathrm{P}_{\mathrm{i} ; \mathrm{t}-1} \quad$ : price of constituent $I$ on the previous day of calculating the index (on the starting day for when $t=1$ )
$\mathrm{Q}_{\mathrm{i}, \mathrm{t}} \quad$ : number of shares included in the index for constituent $I$ at the start of day $t$

Furthermore, the following caveats apply to (4.1):

- Denominator uses today's quantities (post-repayment, ex-price) and yesterday's price (repayment, cum-price)

- In order to prevent discontinuities, yesterday's closing price needs to be adjusted with a Price Adjustment Factor ( $P A F)$, to make it comparable to today's

- $\quad P A F_{i ; t}=$ ex-price $/$ cum-price $=\left(P_{t ; 1}-1\right) / P_{t-1}$

Therefore, (4.1) becomes:

$$
I_{t}^{B}=I_{t-1}^{B} \frac{\sum_{i=1}^{n} P_{i ; t} Q_{i ; t}}{\sum_{i=1}^{n} P_{i ; t-1} Q_{i ; t} P A F_{i ; t}}
$$

$I_{t}^{B}$ gave the dividend-adjusted time series for every bucket, taking into consideration all the stocks belonging to that risk group. The series were effectively used to compute the MCR for each bucket partially employing the methodology advocated by BCBS, 2016, for IMA, which features the calculation of ES. The ES calculation was performed under the broad guidelines contained in BCBS, 2016: daily time horizon ${ }^{5}$, one-tailed 97.50\% confidence level and values starting from the year 2005 at minimum. Given that BCBS did not require a specific model to calculate the risk metric, several approaches are employed: Historical Simulation (HS), GARCH-Normal, GARCH-t(d), EGARCHNormal, EGARCH-t(d), Filtered Historical Simulation (FHS) and GARCH-EVT. HS values are obtained utilising rolling windows, Conditional Models (GARCH-EGARCH) via Maximum Likelihood (ML), FHS through Quasi-ML with GARCH-Normal, GARCH-t(d), EGARCH-Normal and EGARCH-t(d) specifications to generate the distribution of standardised residuals. EVT follows the Peaks-OverThresholds (POT) approach with the Method of Moments (MM) applied to obtain Generalised Pareto Distribution (GPD) parameters after GARCH pre-whitening (McNeil, Frey and Embrechts, 2005, and Embrechts, Klüppelberg and Mikosch, 1997. ES models are checked using the VaR-based Backtesting characteristic of Basel II and Basel III and the newly-enacted Profits and Losses Attribution Tests (P\&LAT), which in practice adds a further element to gauge the accuracy of the representations (BCBS, 2016). The outcomes, then, are plugged into the formula envisaged by the BCBS, 2016, which makes extensive use of the stressed period, though for ES computation rather than the VaR typical of Basel II and Basel III.

The ES models for each risk bucket are afterwards expressed in terms of the MCR formula for ES-based techniques, although modified at some point of the process:

$$
M C R_{t}=\max \left(I M C C_{t-1} ; m_{c} I M C C_{a v g}\right)
$$

\footnotetext{
${ }^{5}$ The BCBS, 2013, explicitly recommends aggregating the returns in blocks of different amount of day in relation with the liquidity of the assets considered. This work purposely leaves aside the BCBS indication acknowledging the fact that that clustering may indeed mask the deficiencies of the schemes tried, much in the same fashion as Danielsson, 2002, states for the Basel II Capital Accord and Rossignolo, Fethi and Shaban, 2013, remark for Basel II and Basel III.
} 
thus making the MCR equal to the maximum of the most recent Internally Modelled Capital Charge (IMCC) and an equally weighted average of the previous 12 weeks (60 days) scaled by a multiplier $m_{c}$. The factor $m_{c}$ is set at a minimum of 1.00 and is susceptible of being enhanced by a penalty determined on the basis of the outcome of the new version of Backtesting (BCBS, 2016), though, in another twist in the regulations, the BCBS also changed the charges for poor Backtesting performance (BCBS, 2016). In order to conserve the notation in BCBS, 2016, IMCC was still kept in (2.1), although it denoted the ES instead of the stressed formulation proposed 6 .

The second variable $\rho_{\mathrm{ij}}$ (correlation parameter between stocks belonging to the same risk bucket) appears in the expression (4.3) below:

$$
K_{b}=\sqrt{\sum_{i} R W_{i}^{2} M V_{i}^{2}+\sum_{i} \sum_{j \neq i} \rho_{i j} R W_{i} M V_{i} R W_{j} M V_{j}}
$$

where:

$\mathrm{K}_{\mathrm{b}} \quad$ : risk exposure for bucket $b$

$\mathrm{RW}_{\mathrm{i}} \quad$ : risk weight of equity $i$

$\mathrm{MV}_{\mathrm{i}} \quad$ : market value of equity $i$

$\rho_{\mathrm{ij}} \quad$ : correlation coefficient between stocks $i$ and $j$ belonging to the same bucket $b$

BCBS did not provide any indication as to the procedure by means of which the correlation coefficient was obtained, and only supplied the information contained in Table 2.

Therefore, the paper proposes to evaluate the outcome varying the sample over which the correlation coefficient was measured, repeating the process for every bucket on the two stock exchanges. For that purpose, the study estimated $\rho$ over the full sample period.

Regarding the third variable, namely the correlation coefficient between different risk buckets $\gamma_{b c}$, it is susceptible of being spotted in formula (3.4), which expresses the Equity Risk Capital $(E R C)$ or, equivalently, the Minimum Capital Requirement applying the SA:

$$
\text { EquityRisk Capital }(E R C)=\sqrt{\sum_{b=1}^{B} K_{b}^{2}+\sum_{b=1}^{B} \sum_{c \neq b}^{B} \gamma_{b c} S_{b} S_{c}}+K_{\text {residual }}
$$

$$
\text { with } S_{b}=\sum_{i \in b} R W_{i} M V_{i}
$$

\footnotetext{
${ }^{6}$ The article stopped short of applying the full procedure for IMA (BCBS, 2016) and, in this sense, two differences could be mentioned: i) the factor $m_{c}$ was set at a minimum of 1.00 instead of 1.50 and, ii) IMCC did not receive the influence of the ES metric in the fashion envisaged by BCBS, 2016:

$I M C C=E S=E S_{R, S} \frac{E S_{F, C}}{E S_{R, C}} \quad$ which indicates that the ES for capital purposes (IMCC) is equal to the ES based on a stressed observation period using a reduced set of risk factors $\left(E S_{R, S}\right)$ multiplied by the ratio of the ES based on the current observation period with a full set of risk factors $\left(E S_{F, C}\right)$ and the current $E S$ calculated with a reduced set of risk factors $\left(E S_{R, C}\right)$. Instead, the paper avoided the stressed escalation, therefore limiting the ES calculation to the choice between the last day ES and the average of the last 60 days ES as in (3.1). Actually, the exact replication appeared unnecessary, given that the BCBS only linked RW to the calculation of ES.
} 
Again, the BCBS did not give inkling to the procedure used to calculate $\gamma_{\mathrm{bc}}$, but provided a matrix with the values for all the risk buckets instead displayed in Table 3.

Utilising the time series of the risk buckets determined by (4.1) over the observation term, the analysis suggested the possibility to find alternative values for the correlation between buckets and evaluated its impact on the SA's ERC.

The research work, consequently, introduced a series of variations to the SA changing the main fixed variables underpinning it: $R W \mathrm{~s}$ by means of the indirect adaptation of the IMA regime using alternative volatility models- to determine the standalone capital requirement of the respective bucket, and the correlation parameters within and across risk buckets.

However, the ultimate practical goal resided in assessing the effect of those variations on the $E R C$ for stock portfolios. Two different strands guided the construction of the sets: Principal Components Analysis (PCA) and Maximum Volatility (MV) as measured by the standard deviation over the sample period; i.e., stocks were selected according to their contribution to the variability of the respective bucket indicated by PCA or MV; within each strand, companies were weighted in accordance with their market capitalisation, prioritising those reporting higher one at the end of the sample period. With a view to broadening the scope of the analysis, both PCA and MV avenues complemented by market capitalisation- featured portfolios containing 20, 8 and 4 assets, comprised by 5,2 and 1 stock per bucket. Synthetically, the procedure discoursed along the following steps:

i) Computation of the rank of species with highest volatility in terms of PCA and MV for risk buckets 5 to 8 ;

ii) Selection of the quantity of shares within the respective risk bucket in accordance to i);

iii) Application of the market capitalisation weighting scheme for the securities previously picked in ii) using the values at the end of the sample period.

The aforementioned criteria, synthesised in Table 4a., produced six portfolios for both the US and UK stock exchanges, depicted in Tables $4 \mathrm{~b}$. to $4 \mathrm{~m}$.

Table 4a. Portfolio selection criteria

\begin{tabular}{|l|c|c|c|c|c|}
\hline Portfolio & $\begin{array}{c}\text { Main } \\
\text { criteria }\end{array}$ & $\begin{array}{c}\text { Quantity of } \\
\text { Stocks }\end{array}$ & $\begin{array}{c}\text { Buckets } \\
\text { Included }\end{array}$ & $\begin{array}{c}\text { Stocks per } \\
\text { Bucket }\end{array}$ & $\begin{array}{c}\text { Weighting } \\
\text { Scheme }\end{array}$ \\
\hline Portfolio 1 & PCA & 20 & $5-8$ & 5 & Market Capitalisation \\
\hline Portfolio 2 & MV & 20 & $5-8$ & 5 & Market Capitalisation \\
\hline Portfolio 3 & PCA & 8 & $5-8$ & 2 & Market Capitalisation \\
\hline Portfolio 4 & MV & 8 & $5-8$ & 2 & Market Capitalisation \\
\hline Portfolio 5 & PCA & 4 & $5-8$ & 1 & Market Capitalisation \\
\hline Portfolio 6 & MV & 4 & $5-8$ & 1 & Market Capitalisation \\
\hline
\end{tabular}

Source: Own elaboration 
Table 4b. UK Portfolio 1

\begin{tabular}{|l|l|c|r|}
\hline No. & \multicolumn{1}{|c|}{ Stock } & $\begin{array}{c}\text { Risk } \\
\text { Bucket }\end{array}$ & Weight \\
\hline 1 & Carnival Group & 5 & $7,49 \%$ \\
\hline 2 & Shire & 5 & $7,16 \%$ \\
\hline 3 & Marks \& Spencer & 5 & $1,90 \%$ \\
\hline 4 & AstraZeneca & 5 & $30,90 \%$ \\
\hline 5 & Informa Group & 5 & $1,02 \%$ \\
\hline 6 & Sky PLC & 6 & $1,36 \%$ \\
\hline 7 & Persimmon & 6 & $1,60 \%$ \\
\hline 8 & Vodafone Group & 6 & $15,08 \%$ \\
\hline 9 & BAE Systems & 6 & $4,07 \%$ \\
\hline 10 & Johnson Matthews & 6 & $1,40 \%$ \\
\hline 11 & Anglo American & 7 & $1,08 \%$ \\
\hline 12 & BHP Billiton & 7 & $11,40 \%$ \\
\hline 13 & CRH & 7 & $4,16 \%$ \\
\hline 14 & Rolls Royce & 7 & $2,72 \%$ \\
\hline 15 & Mondi & 7 & $1,67 \%$ \\
\hline 16 & Smiths Group & 8 & $0,95 \%$ \\
\hline 17 & 3I Group & 8 & $1,20 \%$ \\
\hline 18 & Sage Group & 8 & $1,67 \%$ \\
\hline 19 & RSA Insurance Group & 8 & $1,11 \%$ \\
\hline 20 & Schroders & 8 & $2,06 \%$ \\
\hline
\end{tabular}

Source: Own elaboration

Table 4c. UK Portfolio 2

\begin{tabular}{|l|l|c|r|}
\hline No. & \multicolumn{1}{|c|}{ Stock } & $\begin{array}{c}\text { Risk } \\
\text { Bucket }\end{array}$ & Weight \\
\hline 1 & Ashtead Group & 5 & $1,34 \%$ \\
\hline 2 & Unilever & 5 & $20,93 \%$ \\
\hline 3 & ITV & 5 & $2,65 \%$ \\
\hline 4 & Dixons Carphone & 5 & $1,37 \%$ \\
\hline 5 & EasyJet & 5 & $1,64 \%$ \\
\hline 6 & Sky PLC & 6 & $13,95 \%$ \\
\hline 7 & Vodafone Group & 6 & $4,54 \%$ \\
\hline 8 & BAE Systems & 6 & $3,76 \%$ \\
\hline 9 & GKN & 6 & $1,26 \%$ \\
\hline 10 & Persimmon & 6 & $1,48 \%$ \\
\hline 11 & BHP Billiton & 7 & $10,54 \%$ \\
\hline 12 & Randgold Resources & 7 & $0,92 \%$ \\
\hline 13 & British Petroleum & 7 & $15,47 \%$ \\
\hline 14 & British Telecom Group & 7 & $9,38 \%$ \\
\hline 15 & Rolls Royce & 7 & $2,51 \%$ \\
\hline 16 & Smiths Group & 8 & $0,88 \%$ \\
\hline 17 & ARM Holdings & 8 & $3,47 \%$ \\
\hline 18 & Hammerson & 8 & $1,12 \%$ \\
\hline 19 & Sage Group & 8 & $1,55 \%$ \\
\hline 20 & St. James's Place & 8 & $1,26 \%$ \\
\hline
\end{tabular}

Source: Own elaboration 
Table 4d. UK Portfolio 3

\begin{tabular}{|c|l|c|r|}
\hline No. & \multicolumn{1}{|c|}{ Stock } & $\begin{array}{c}\text { Risk } \\
\text { Bucket }\end{array}$ & \multicolumn{1}{c|}{ Weight } \\
\hline 1 & Carnival Group & 5 & $23,23 \%$ \\
\hline 2 & Shire & 5 & $22,19 \%$ \\
\hline 3 & Sky PLC & 6 & $4,21 \%$ \\
\hline 4 & Persimmon & 6 & $4,96 \%$ \\
\hline 5 & Anglo American & 7 & $3,35 \%$ \\
\hline 6 & BHP Billiton & 7 & $35,36 \%$ \\
\hline 7 & Smiths Group & 8 & $2,96 \%$ \\
\hline 8 & 3I Group & 8 & $3,73 \%$ \\
\hline
\end{tabular}

Source: Own elaboration

Table 4e. UK Portfolio 4

\begin{tabular}{|c|l|c|c|}
\hline No. & \multicolumn{1}{|c|}{ Stock } & $\begin{array}{c}\text { Risk } \\
\text { Bucket }\end{array}$ & Weight \\
\hline 1 & Ashtead Group & 5 & $2,37 \%$ \\
\hline 2 & Unilever & 5 & $36,99 \%$ \\
\hline 3 & Sky PLC & 6 & $24,66 \%$ \\
\hline 4 & Vodafone Group & 6 & $8,03 \%$ \\
\hline 5 & BHP Billiton & 7 & $18,64 \%$ \\
\hline 6 & Randgold Resources & 7 & $1,62 \%$ \\
\hline 7 & Smiths Group & 8 & $1,56 \%$ \\
\hline 8 & ARM Holdings & 8 & $6,13 \%$ \\
\hline
\end{tabular}

Source: Own elaboration

Table 4f. UK Portfolio 5

\begin{tabular}{|c|l|c|r|}
\hline & \multicolumn{1}{|c|}{ Stock } & $\begin{array}{c}\text { Risk } \\
\text { Bucket }\end{array}$ & Weight \\
\hline 1 & Carnival Group & 5 & $68,83 \%$ \\
\hline 2 & Sky PLC & 6 & $12,48 \%$ \\
\hline 3 & Anglo American & 7 & $9,92 \%$ \\
\hline 4 & Smiths Group & 8 & $8,77 \%$ \\
\hline
\end{tabular}

Source: Own elaboration

Table 4f. UK Portfolio 5

\begin{tabular}{|c|l|c|r|}
\hline No. & \multicolumn{1}{|c|}{ Stock } & $\begin{array}{c}\text { Risk } \\
\text { Bucket }\end{array}$ & Weight \\
\hline 1 & Ashtead Group & 5 & $5,01 \%$ \\
\hline 2 & Sky PLC & 6 & $52,22 \%$ \\
\hline 3 & BHP Billiton & 7 & $39,47 \%$ \\
\hline 4 & Smiths Group & 8 & $3,30 \%$ \\
\hline
\end{tabular}

Source: Own elaboration 
Table 4h. US Portfolio 1

\begin{tabular}{|l|l|c|r|}
\hline No. & \multicolumn{1}{|c|}{ Stock } & $\begin{array}{c}\text { Risk } \\
\text { Bucket }\end{array}$ & Weight \\
\hline 1 & Walt Disney & 5 & $4,62 \%$ \\
\hline 2 & Merck \& Co & 5 & $3,92 \%$ \\
\hline 3 & Coca- Cola & 5 & $4,97 \%$ \\
\hline 4 & Procter Gamble & 5 & $5,71 \%$ \\
\hline 5 & WalMart & 5 & $5,22 \%$ \\
\hline 6 & Microsoft & 6 & $11,78 \%$ \\
\hline 7 & 3 M & 6 & $2,47 \%$ \\
\hline 8 & Intel & 6 & $4,32 \%$ \\
\hline 9 & Du Pont & 6 & $1,55 \%$ \\
\hline 10 & IBM & 6 & $3,55 \%$ \\
\hline 11 & Caterpillar & 7 & $1,05 \%$ \\
\hline 12 & GE & 7 & $8,37 \%$ \\
\hline 13 & Exxon Mobil & 7 & $8,63 \%$ \\
\hline 14 & Boeing & 7 & $2,58 \%$ \\
\hline 15 & Chevron & 7 & $4,50 \%$ \\
\hline 16 & Goldman Sachs & 8 & $2,04 \%$ \\
\hline 17 & Travelers & 8 & $0,91 \%$ \\
\hline 18 & Apple & 8 & $15,52 \%$ \\
\hline 19 & JPMorgan & 8 & $6,46 \%$ \\
\hline 20 & American Express & $1,82 \%$ \\
\hline
\end{tabular}

Source: Own elaboration

Table 4i. US Portfolio 2

\begin{tabular}{|l|l|c|r|}
\hline No. & \multicolumn{1}{|c|}{ Stock } & $\begin{array}{r}\text { Risk } \\
\text { Bucket }\end{array}$ & Weight \\
\hline 1 & Home Depot & 5 & $1,62 \%$ \\
\hline 2 & Walt Disney & 5 & $2,22 \%$ \\
\hline 3 & Nike & 5 & $1,16 \%$ \\
\hline 4 & Merck \& Co & 5 & $4,58 \%$ \\
\hline 5 & WalMart & 5 & $2,22 \%$ \\
\hline 6 & Intel & 6 & $5,67 \%$ \\
\hline 7 & Microsoft & 6 & $12,09 \%$ \\
\hline 8 & IBM & 6 & $5,42 \%$ \\
\hline 9 & Du Pont & 6 & $1,43 \%$ \\
\hline 10 & 3 M & 7 & $2,19 \%$ \\
\hline 11 & Caterpillar & 7 & $1,66 \%$ \\
\hline 12 & Boeing & 7 & $2,47 \%$ \\
\hline 13 & UTC & 7 & $2,73 \%$ \\
\hline 14 & GE & 7 & $13,50 \%$ \\
\hline 15 & Exxon Mobil & 8 & $5,27 \%$ \\
\hline 16 & JPMorgan & 8 & $6,23 \%$ \\
\hline 17 & Apple & 8 & $5,90 \%$ \\
\hline 18 & Cisco Systems & 8 & $3,07 \%$ \\
\hline 19 & Goldman Sachs & $2,19 \%$ \\
\hline 20 & American Express & \\
\hline
\end{tabular}

Source: Own elaboration 
Table 4j. US Portfolio 3

\begin{tabular}{|l|l|c|r|}
\hline No. & \multicolumn{1}{|c|}{ Stock } & $\begin{array}{c}\text { Risk } \\
\text { Bucket }\end{array}$ & Weight \\
\hline 1 & Walt Disney & 5 & $13,1 \%$ \\
\hline 2 & Merck \& Co & 5 & $11,2 \%$ \\
\hline 3 & Microsoft & 5 & $33,5 \%$ \\
\hline 4 & $3 \mathrm{M}$ & 5 & $7,0 \%$ \\
\hline 5 & Caterpillar & 5 & $3,0 \%$ \\
\hline 6 & GE & 6 & $23,8 \%$ \\
\hline 7 & Goldman Sachs & 6 & $5,8 \%$ \\
\hline 8 & Travelers & 6 & $2,6 \%$ \\
\hline
\end{tabular}

Source: Own elaboration

Table 4k. US Portfolio 4

\begin{tabular}{|l|l|c|r|}
\hline No. & \multicolumn{1}{|c|}{ Stock } & $\begin{array}{r}\text { Risk } \\
\text { Bucket }\end{array}$ & \multicolumn{1}{|c|}{ Weight } \\
\hline 1 & Home Depot & 5 & $5,52 \%$ \\
\hline 2 & Merck \& Co & 5 & $11,39 \%$ \\
\hline 3 & Intel & 5 & $14,11 \%$ \\
\hline 4 & Microsoft & 5 & $30,08 \%$ \\
\hline 5 & Caterpillar & 5 & $4,13 \%$ \\
\hline 6 & Boeing & 6 & $6,16 \%$ \\
\hline 7 & JPMorgan & 6 & $13,11 \%$ \\
\hline 8 & Apple & 6 & $15,50 \%$ \\
\hline
\end{tabular}

Source: Own elaboration

Table 41. US Portfolio 5

\begin{tabular}{|l|l|c|r|}
\hline No. & \multicolumn{1}{|c|}{ Stock } & $\begin{array}{c}\text { Risk } \\
\text { Bucket }\end{array}$ & Weight \\
\hline 1 & Walt Disney & 5 & $23,69 \%$ \\
\hline 2 & Microsoft & 5 & $60,43 \%$ \\
\hline 3 & Caterpillar & 5 & $5,40 \%$ \\
\hline 4 & Goldman Sachs & 5 & $10,48 \%$ \\
\hline
\end{tabular}

Source: Own elaboration

Table 4m. US Portfolio 6

\begin{tabular}{|l|l|c|c|}
\hline No. & \multicolumn{1}{|c|}{ Stock } & $\begin{array}{c}\text { Risk } \\
\text { Bucket }\end{array}$ & Weight \\
\hline 1 & Home Depot & 5 & $14,97 \%$ \\
\hline 2 & Intel & 5 & $38,27 \%$ \\
\hline 3 & Caterpillar & 5 & $11,21 \%$ \\
\hline 4 & JPMorgan & 5 & $35,55 \%$ \\
\hline
\end{tabular}

Source: Own elaboration 
Primary data concerning stock prices, quantity of outstanding shares and market capitalisation were retrieved from Thomson Reuters $₫$, portfolios and indices time series were afterwards converted to relative values using logarithmic returns ${ }^{7}$. Furthermore, the data set was then split into two periods for parameter estimation (dating back at least to 2005 (BCBS, 2016) and evaluation of market risk forecasts (one year minimum), thus complying with Basel indications: in this sense, the sample period spanned 5 years (2003-2007) while the forecast or backtest term was the year 2008, which provided a real-time check and therefore avoided arbitrary assumptions about any kind of market slump.

Given the fact that there seems no objective procedure to establish the appropriate capital base, it seems reasonable to evaluate that level in terms of the heaviest loss recorded in the stress or backtest period. Consequently, the study made extensive use of the greatest shortfall of the backtest year as well as a measure of the coverage called Loss Coverage Ratio $(L C R)$, first put forward by Rossignolo, Fethi and Shaban, 2012. The exercise was carried out considering the recipe indicated by BCBS (fixed $R W$ and correlation coefficients $\rho$ and $\gamma$ ) and applying a simulation analysis with the ensuing characteristics:

i) Replacement of the fixed $R W$ coefficient with ES calculated through a variety of models including Filtered Historical Simulation GARCH and EGARCH with Normal and Student-t distributions for Maximum Likelihood (ML) estimation, Conditional Volatility GARCH and EGARCH with Normal and Student-t distributions for ML computation and residual distributions and Extreme Value Theory (EVT) via Peaks-Over-Threshold (POT) (Coles (2001)) after GARCH-Normal pre-whitening (McNeil, Frey and Embrechts (2007)). Notably, ES is calculated for the series of indices belonging to every risk bucket (3.1) instead of the rather opaque and confusing criterion utilised by BCBS;

ii) Substitution of the correlation coefficient within the risk bucket $(\rho)$ for the certain percentiles of the (empirical) correlation coefficients of the positions in the respective risk bucket;

iii) Replacement of the correlation coefficient between two risk buckets $(\gamma)$ with the (empirical) correlation coefficient verified between two indices -calculated as in (3.1)-, each one representative of two risk buckets.

The simulation analysis was performed changing all the variables in unison $(R W, \rho$, and $\gamma)$ and combining one or two changes with the official values ruled by BCBS.

Finally, the research suggests the adoption of suitable solutions for the variables concerned in case the national regulators should deem the final ERC disproportionate to attend the stressed demands of the portfolios in question, embodied in the insertion of a calibration parameter (sa) in expression (4.4):

$$
\text { EquityRisk Capital }(E R C)=(s a)\left(\sqrt{\sum_{b=1}^{B} K_{b}^{2}+\sum_{b=1}^{B} \sum_{c \neq b}^{B} \gamma_{b c} S_{b} S_{c}}+K_{\text {residual }}\right)
$$

\footnotetext{
${ }^{7}$ Thus implementing a passive portfolio management (Christoffersen, 2003), i.e., rebalancing to constant weights strategy (Alexander, 2008).
} 
with $S_{b}$ conserving the meaning in (3.5). The coefficient, while not altering BCBS's formulation, would, in principle, allow the respective supervisors to tailor the ERC according to the desired level considering a pre-specified $L C R$ multiple.

\section{Results}

The comprehensive overhaul of the SA provides outcomes worth of being carefully evaluated, particularly in view of the fact that the SA constitutes the so-called 'credible fall-back' to the much more sophisticated IMA. It is important to note, previous to the analysis of the results, which on the grounds of practicality and space restrictions, the outcome will be provided averaging the figures obtained for all portfolios ${ }^{8}$.

In the latest market risk reform, the BCBS is making a case of the stressed calibration, both for the SA and the IMA, and, as such, it is important to consider the portfolios' heaviest losses as a pivot or yardstick. In this vein, in the interests of tractability and acknowledging the drawbacks of averaging, DJIA's portfolios sustained heavier losses than its FTSE's counterparts $10.50 \%$ against $8.45 \%$, or $+24.28 \%$ in Tables 5 and 6, Columns [7]) hence delivering higher ERC. However, in terms of BCBS's SA, that difference did not appear reflected in the $E R C(30.62 \%$ vs $29.23 \%$, or, $+4.75 \%$ in Tables 5 and 6, Columns [8]), which, in principle, suggested that the BCBS produced a relatively insensitive formula. Furthermore, when evaluated in terms of the $L C R$, BCBS's SA seemed to deliver excessive capital requirements, given that, in both instances, the figure situated beyond 3.50 (3.65 in the US and 3.53 in the UK in Tables 5 and 6, Columns [10]), which meant that the ERC covered more than three and a half times the greatest loss at the time of the subprime crisis of 2008. In principle, the SA could be delivering somewhat high $E R C$, thus sparking the argument about that excessiveness and further ways to reduce that largeness.

Even within the boundaries of the appraisal, the results would imply the existence of room for refinement if the factors $R W, \rho$ and $\gamma$ varied either individually or in unison. In this vein, the outcomes show that the most radical differences surge when the standalone capital requirements $R W$ are altered. In the UK exercise, 66 out of 76 (87\%) examples using models to calculate $R W$ delivered $E R C$ smaller than the official SA (Table 5, Column [9]) but still with substantial coverage in terms of the $\operatorname{LCR}$ (2.67 to 3.41, smallest and highest respectively in Table 5, Column [11]), whereas for the US the situation did not seem so clear despite which changing $R W$ provided an economy in terms of $E R C$ in 18 out of 76 instances (24\%) (Table 6, Column [9]), also yielding appreciable LCR values in excess of 2.71 (Table 6, Column [11]).

The correlation between buckets and within buckets might be useful in driving down the excessive $E R C$, although in combination with variable $R W \mathrm{~s}$ as they reveal incapable of producing relevant changes to BCBS's SA. For portfolios belonging to FTSE, the correlation coefficient between buckets $(\gamma)$, combined with CV/EGARCH-t as the ES model $(R W)$ and Basel's correlation within buckets delivered almost 27.79\% less ERC than the BCBS's counterpart (Table 5, Line [1], Column [12]). The correlation coefficient within the risk buckets followed suit using a $50 \%$ percentile conjointly with FHS/EGARCH-t as $R W$ specification and Basel's correlation between buckets, giving

\footnotetext{
${ }^{8}$ However, the detailed results are available at requirement.
} 
a similar $E R C$ (27.28\% smaller than the official SA), albeit with $L C R=2.75$ (Table 5, Line [2], Column [12]). In the US only the correlation coefficient between buckets seemed significant to reduce the capital excessiveness, though allied with CV/EGARCH-t and BCBS's $\rho$, yielding $7.06 \%$ less ERC than the official SA and 2.74 LCR (Table 6, Line [9], Columns [12] and [11] respectively). On the other hand, the correlation within buckets at 50\% percentile, coupled with CV/EGARCH-t and Basel's correlation between buckets fails to drive down ERC and gives an ERC 19\% greater than BCBS's SA, with 3.52 LCR (Table 6, Line [19], Columns [12] and [11] respectively).

As the results convey, the construction of SA lends itself to lots of combinations and mixtures of variables. One element susceptible of being highlighted is the representation chosen to carry out the $R W$ modelling as, in effect, it appeared that at the time of calculating the standard stressed ES $(R W)$, EVT-POT yielded similar results to the official recipe. It is convenient to underline that this technique was the one that passed Backtesting all across the board without any surcharge, i.e., for all the risk buckets in each country, and, as such, its outcome was undistorted by BCBS penalties for poor Backtesting performance; on the other hand, the remaining specifications were tainted by extra capital, thus masking their true behaviour. For UK portfolios, EVT-POT plus BCBS's correlation coefficients managed an ERC 6.27\% less than Basel Committee (Table 5, Line [70], Column [12]), but a fully changed setting using EVT-POT, recalculating $\gamma$, and fixing empirical $\rho$ at $90 \%$ delivers 35.58\% ERC, $+20.36 \%$ vis a vis BCBS (Table 5, Line [37], Column [12]). DJIA based portfolios gave a similar outcome, with EVT-POT and Basel's correlation parameters yielding 6.72\% less ERC than BCBS, again with a substantial $L C R$ of 3.40 (Table 6, Line [11], Columns [12] and [11] respectively). Much like the former UK's example, a fully revamped configuration using EVT-POT and $\rho$ at 75\% percentile delivered approximately $30 \%$ more $E R C$ (39.78\% versus $30.62 \%)$, aggravating the capital largeness (Table 6, Line [56], Columns [12], [9] and [8] respectively).

Unfortunately, it is impossible to know the precise procedure followed by the BCBS at the time of establishing the standard value of $R W$ s given the fact that the only explanation is "...the average of the stressed ES..." (BCBS, 2013, p.34) but the results suggested that EVT-POT plus the official correlation coefficients were the values that best approximated BCBS's recipe. As it might be presupposed, the remaining techniques delivered smaller values of $E R C$ unless they were coupled with higher percentiles of correlation parameters within buckets (for instance, a $90 \%$ percentile) or, in case of lower ones, the combination should feature the empirical correlation between buckets (normally higher than BCBS's).

Although the task of findings regularities across the endless possibilities may appear in principle cumbersome, some important evidences and their subsequent effect on the capital levels could not be neglected: i) ultra heavy-tailed models like EVT-POT produced the outcome closest to BCBS's SA disregarding the correlation parameters; ii) other schemes like those stemming from CV or FHS may have been used to attune the resulting capital levels with the desired regulatory stance; iii) the correlation parameter within buckets followed an approximate linear relationship with the percentile associated in terms of the $E R C$, and their impact could result softened applying RWs schemes; iv) the correlation parameter between buckets did not seem so effective at the time of influencing the $E R C$, and that effect could be applied to intensify or dampen the clout of the rest of the variables, particularly $R W$.

Finally, acknowledging that for some regulators the analysis of the empirical nature of the SA might turn an uphill task in view of the complexity of the calculations involved, the study proposes 
the adoption of a more conventional recipe characterised by the introduction of a calibration parameter $(s a)$ in the official SA formulation (2.7). In this sense, supervisors should pivot around the $L C R$, prefixing a value and setting the adjustment that could drive the capital requirement to amounts more in line with the reality of the market concerned. In this vein, for instance, the US watchdog may decide that an $E R C$ covering two times the heaviest loss of the stressed period is enough according to the business cycle, automatically meaning that the sa should be adjusted to $68.58 \%$ of the full value and (Table 8, Line [11], Column [5]), similarly, the UK controller could demand that banks should cover 2.5 times the greatest loss experienced in 2008, consequently making sa=72.26\% (Table 7, Line [16], Column [5]), thus conveying the idea of the flexibility and adaptability of the appraisal put forward.

Table 5._Results of the simulation analysis - UK

\begin{tabular}{|c|c|c|c|c|c|c|c|c|c|c|c|}
\hline $\begin{array}{c}\text { Case } \\
N^{\circ} \\
{[1]}\end{array}$ & $\begin{array}{c}\text { Risk Weight } \\
\text { Model } \\
{[2]}\end{array}$ & $\begin{array}{c}\text { SA } \\
\text { RW } \\
{[3]}\end{array}$ & $\begin{array}{c}\text { SA } \\
\rho \\
{[4]}\end{array}$ & $\begin{array}{c}\text { SA } \\
\gamma \\
{[5]}\end{array}$ & $\begin{array}{c}\text { SA } \\
P \\
{[6]}\end{array}$ & $\begin{array}{c}\text { Max. } \\
\text { Loss } \\
{[7]}\end{array}$ & $\begin{array}{c}\text { ERC } \\
\text { SA(B) } \\
{[8]}\end{array}$ & $\begin{array}{c}\text { ERC } \\
\text { SA(A) } \\
{[9]}\end{array}$ & $\begin{array}{c}\text { LCR } \\
\text { SA(B) } \\
{[10]}\end{array}$ & $\begin{array}{c}\text { LCR } \\
\text { SA(A) } \\
{[11]}\end{array}$ & $\begin{array}{l}\text { LCR } \\
\text { Var. } \\
\text { [12] }\end{array}$ \\
\hline 1 & CV/EGARCH-t & A & $\mathrm{B}$ & $\mathrm{A}$ & 0,75 & $8,45 \%$ & $29,23 \%$ & $21,84 \%$ & 3,5278 & 2,7313 & $-27,79 \%$ \\
\hline 2 & FHS/EGARCH-t & $\mathrm{A}$ & $\mathrm{B}$ & $\mathrm{A}$ & 0,75 & $8,45 \%$ & $29,23 \%$ & $21,97 \%$ & 3,5278 & 2,7459 & $-27,28 \%$ \\
\hline 3 & FHS/EGARCH-N & A & B & A & 0,75 & $8,45 \%$ & $29,23 \%$ & $22,02 \%$ & 3,5278 & 2,7505 & $-27,07 \%$ \\
\hline 4 & CV/GARCH-t & $\mathrm{A}$ & $\mathrm{B}$ & $\mathrm{A}$ & 0,75 & $8,45 \%$ & $29,23 \%$ & $22,09 \%$ & 3,5278 & 2,7595 & $-26,86 \%$ \\
\hline 5 & FHS/GARCH-t & A & $\mathrm{B}$ & $\mathrm{A}$ & 0,75 & $8,45 \%$ & $29,23 \%$ & $22,25 \%$ & 3,5278 & 2,7760 & $-26,28 \%$ \\
\hline 6 & FHS/GARCH-N & A & B & A & 0,75 & $8,45 \%$ & $29,23 \%$ & $22,36 \%$ & 3,5278 & 2,7878 & $-25,82 \%$ \\
\hline 7 & CV/EGARCH-N & $\bar{A}$ & $\mathrm{~B}$ & $\mathrm{~A}$ & 0,75 & $8,45 \%$ & $29,23 \%$ & $22,37 \%$ & 3,5278 & 2,7885 & $-25,80 \%$ \\
\hline 8 & CV/EGARCH-t & A & A & A & 0,50 & $8,45 \%$ & $29,23 \%$ & $22,47 \%$ & 3,5278 & 2,8078 & $-25,75 \%$ \\
\hline 9 & FHS/EGARCH-t & $\bar{A}$ & $\bar{A}$ & $\bar{A}$ & 0,50 & $8,45 \%$ & $29,23 \%$ & $22,61 \%$ & 3,5278 & 2,8223 & $-25,23 \%$ \\
\hline 10 & FHS/EGARCH-N & $\bar{A}$ & $\bar{A}$ & $\bar{A}$ & 0,50 & $8,45 \%$ & $29,23 \%$ & $22,66 \%$ & 3,5278 & 2,8269 & $-25,02 \%$ \\
\hline 11 & CV/GARCH-t & A & A & A & 0,50 & $8,45 \%$ & $29,23 \%$ & $22,72 \%$ & 3,5278 & 2,8357 & $-24,81 \%$ \\
\hline 12 & FHS/GA & $\mathrm{A}$ & $\mathrm{A}$ & $\bar{A}$ & 0,50 & $8,45 \%$ & $29,23 \%$ & $22,88 \%$ & 3,5278 & 2,8521 & $-24,24 \%$ \\
\hline 13 & CV/GARCH-N & $\bar{A}$ & $\mathrm{~B}$ & $\bar{A}$ & 0,75 & $8,45 \%$ & $29,23 \%$ & $22,87 \%$ & 3,5278 & 2,8433 & $-23,96 \%$ \\
\hline 14 & FHS/GARCH-N & $\mathrm{A}$ & A & $\mathrm{A}$ & 0,50 & $8,45 \%$ & $29,23 \%$ & $22,99 \%$ & 3,5278 & 2,8638 & $-23,78 \%$ \\
\hline 15 & CV/EGARCH-N & A & $\bar{A}$ & $\bar{A}$ & 0,50 & $8,45 \%$ & $29,23 \%$ & $23,00 \%$ & 3,5278 & 2,8645 & $-23,77 \%$ \\
\hline 16 & CV/GARCH-N & $\bar{A}$ & $\bar{A}$ & $\bar{A}$ & 0,50 & $8,45 \%$ & $29,23 \%$ & & 3,5278 & 2,9190 & $-21,93 \%$ \\
\hline 17 & CV/EGARCH-t & A & A & A & 0,75 & $8,45 \%$ & $29,23 \%$ & $25,08 \%$ & 3,5278 & 3,1387 & $-17,28 \%$ \\
\hline 18 & FHS/EGARCH-t & $\mathrm{A}$ & $\bar{A}$ & $\bar{A}$ & 0,75 & $8,45 \%$ & $29,23 \%$ & $25,22 \%$ & 3,5278 & 3,1530 & $-16,77 \%$ \\
\hline 19 & FHS/EGARCH-N & A & A & A & 0,75 & $8,45 \%$ & $29,23 \%$ & $25,27 \%$ & 3,5278 & 3,1575 & $-16,57 \%$ \\
\hline 20 & CV/GARCH-t & A & $\mathrm{A}$ & $\bar{A}$ & 0,75 & & $29,23 \%$ & & 3,5278 & 3,1660 & $-16,37 \%$ \\
\hline 21 & FHS/GARCH-t & $\mathrm{A}$ & $\mathrm{A}$ & $\bar{A}$ & 0,75 & $8,45 \%$ & $29,23 \%$ & $25,48 \%$ & 3,5278 & 3,1820 & $-15,81 \%$ \\
\hline 22 & FHS/GARCH-N & A & A & A & 0,75 & $8,45 \%$ & $29,23 \%$ & $25,59 \%$ & 3,5278 & 3,1933 & $-15,36 \%$ \\
\hline 23 & CV/EGARCH-N & A & $\mathrm{A}$ & $\mathrm{A}$ & 0,75 & $8,45 \%$ & $29,23 \%$ & $25,60 \%$ & 3,5278 & 3,1940 & $-15,34 \%$ \\
\hline 24 & CV/GARCH-N & $\mathrm{A}$ & $\mathrm{A}$ & $\bar{A}$ & 0,75 & $8,45 \%$ & $29,23 \%$ & $26,08 \%$ & 3,5278 & 3,2469 & $-13,54 \%$ \\
\hline 25 & $\mathrm{CV} / \mathrm{EGARCH}-\mathrm{t}$ & A & A & A & 0,90 & $8,45 \%$ & $29,23 \%$ & $27,25 \%$ & 3,5278 & 3,4125 & $-10,28 \%$ \\
\hline 26 & FHS/EGARCH-t & A & A & $\bar{A}$ & 0,90 & $8,45 \%$ & $29,23 \%$ & $27,38 \%$ & 3,5278 & 3,4266 & $-9,78 \%$ \\
\hline 27 & FHS/EGARCH-N & A & A & $\bar{A}$ & 0,90 & $8,45 \%$ & $29,23 \%$ & $27,43 \%$ & 3,5278 & 3,4310 & $-9,57 \%$ \\
\hline 28 & CV/GARCH-t & A & $\mathrm{A}$ & $\mathrm{A}$ & 0,90 & $8,45 \%$ & $29,23 \%$ & $27,49 \%$ & 3,5278 & 3,4393 & $-9,38 \%$ \\
\hline 29 & FHS/GARCH-t & $\mathrm{A}$ & A & $\mathrm{A}$ & 0,90 & $8,45 \%$ & $29,23 \%$ & $27,64 \%$ & 3,5278 & 3,4551 & $-8,82 \%$ \\
\hline 30 & FHS/GARCH-N & A & A & $\mathrm{A}$ & 0,90 & $8,45 \%$ & $29,23 \%$ & $27,75 \%$ & 3,5278 & 3,4662 & $-8,38 \%$ \\
\hline 31 & CV/EGARCH-N & $\mathrm{A}$ & A & $\mathrm{A}$ & 0,90 & $8,45 \%$ & $29,23 \%$ & $27,75 \%$ & 3,5278 & 3,4668 & $-8,37 \%$ \\
\hline 32 & CV/GARCH-N & A & A & A & 0,90 & $8,45 \%$ & $29,23 \%$ & $28,23 \%$ & 3,5278 & 3,5187 & $-6,60 \%$ \\
\hline 33 & & A & $\mathrm{B}$ & $\mathrm{A}$ & 0,75 & $8,45 \%$ & $29,23 \%$ & $30,73 \%$ & 3,5278 & 3,7264 & $4,67 \%$ \\
\hline 34 & & A & A & $\mathrm{A}$ & 0,50 & & $29,23 \%$ & $31,29 \%$ & 3,5278 & 3,7934 & $6,46 \%$ \\
\hline 35 & EVT-POT & A & A & A & 0,75 & $8,45 \%$ & $29,23 \%$ & $33,61 \%$ & 3,5278 & 4,0880 & $13,99 \%$ \\
\hline 36 & BCBS & B & $\mathrm{B}$ & A & 0,75 & $8,45 \%$ & $29,23 \%$ & $33,54 \%$ & 3,5278 & 4,0478 & $14,74 \%$ \\
\hline 37 & EVT-POT & A & A & A & 0,90 & $8,45 \%$ & $29,23 \%$ & $35,58 \%$ & 3,5278 & 4,3368 & $20,36 \%$ \\
\hline
\end{tabular}


Revista Mexicana de Economía y Finanzas, Nueva Época, Vol. 16 TNEA, pp. 1- 27, e539

DOI: https://doi.org/10.21919/remef.v16i0.539

\begin{tabular}{|c|c|c|c|c|c|c|c|c|c|c|c|}
\hline 38 & CV/EGARCH-t & $\mathrm{A}$ & $\mathrm{B}$ & B & 0,75 & $8,45 \%$ & $29,23 \%$ & $21,30 \%$ & 3,5278 & 2,6698 & $-29,75 \%$ \\
\hline 39 & FHS/EGARCH-t & A & $\mathrm{B}$ & $\mathrm{B}$ & 0,75 & $8,45 \%$ & $29,23 \%$ & $21,42 \%$ & 3,5278 & 2,6826 & $-29,28 \%$ \\
\hline 40 & FHS/EGARCH-N & A & $\mathrm{B}$ & $\mathrm{B}$ & 0,75 & $8,45 \%$ & $29,23 \%$ & $21,47 \%$ & 3,5278 & 2,6876 & $-29,05 \%$ \\
\hline 41 & CV/GARCH-t & A & B & B & 0,75 & $8,45 \%$ & $29,23 \%$ & $21,50 \%$ & 3,5278 & 2,6914 & $-29,00 \%$ \\
\hline 42 & FHS/GARCH-t & $\mathrm{A}$ & $\mathrm{B}$ & $\mathrm{B}$ & 0,75 & $8,45 \%$ & $29,23 \%$ & $21,62 \%$ & 3,5278 & 2,7047 & $-28,52 \%$ \\
\hline 43 & CV/EGARCH-N & A & $\mathrm{B}$ & $\mathrm{B}$ & 0,75 & $8,45 \%$ & $29,23 \%$ & $21,71 \%$ & 3,5278 & 2,7131 & $-28,16 \%$ \\
\hline 44 & FHS/GARCH-N & A & $\mathrm{B}$ & $\mathrm{B}$ & 0,75 & $8,45 \%$ & $29,23 \%$ & $21,72 \%$ & 3,5278 & 2,7142 & $-28,11 \%$ \\
\hline 45 & CV/EGARCH-t & A & $\mathrm{A}$ & $\mathrm{B}$ & 0,50 & $8,45 \%$ & $29,23 \%$ & $21,94 \%$ & 3,5278 & 2,7471 & $-27,68 \%$ \\
\hline 46 & FHS/EGARCH-t & A & A & B & 0,50 & $8,45 \%$ & $29,23 \%$ & $22,06 \%$ & 3,5278 & 2,7599 & $-27,21 \%$ \\
\hline 47 & FHS/EGARCH-N & $\mathrm{A}$ & $\mathrm{A}$ & $\mathrm{B}$ & 0,50 & $8,45 \%$ & $29,23 \%$ & $22,11 \%$ & 3,5278 & 2,7649 & $-26,98 \%$ \\
\hline 48 & CV/GARCH-t & $\mathrm{A}$ & $\mathrm{A}$ & $\mathrm{B}$ & 0,50 & $8,45 \%$ & $29,23 \%$ & $22,14 \%$ & 3,5278 & 2,7686 & $-26,94 \%$ \\
\hline 49 & CV/GARCH-N & A & B & B & 0,75 & $8,45 \%$ & $29,23 \%$ & $22,09 \%$ & 3,5278 & 2,7542 & $-26,71 \%$ \\
\hline 50 & FHS/GARCH-t & $\mathrm{A}$ & $\mathrm{A}$ & $\mathrm{B}$ & 0,50 & $8,45 \%$ & $29,23 \%$ & $22,26 \%$ & 3,5278 & 2,7819 & $-26,45 \%$ \\
\hline 51 & CV/EGARCH-N & $\mathrm{A}$ & $\mathrm{A}$ & $\mathrm{B}$ & 0,50 & $8,45 \%$ & $29,23 \%$ & $22,35 \%$ & 3,5278 & 2,7902 & $-26,10 \%$ \\
\hline 52 & FHS/GARCH-N & A & A & B & 0,50 & $8,45 \%$ & $29,23 \%$ & $22,36 \%$ & 3,5278 & 2,7914 & $-26,05 \%$ \\
\hline 53 & CV/GARCH-N & $\mathrm{A}$ & $\mathrm{A}$ & $\mathrm{B}$ & 0,50 & $8,45 \%$ & $29,23 \%$ & $22,73 \%$ & 3,5278 & 2,8313 & $-24,65 \%$ \\
\hline 54 & CV/EGARCH-t & $\mathrm{A}$ & $\mathrm{A}$ & $\mathrm{B}$ & 0,75 & $8,45 \%$ & $29,23 \%$ & $24,57 \%$ & 3,5278 & 3,0811 & $-19,14 \%$ \\
\hline 55 & FHS/EGARCH-t & $\bar{A}$ & $\mathrm{~A}$ & $\bar{B}$ & 0,75 & $8,45 \%$ & $29,23 \%$ & $24,70 \%$ & 3,5278 & 3,0938 & $-18,67 \%$ \\
\hline 56 & FHS/EGARCH-N & $\mathrm{A}$ & $\mathrm{A}$ & $\mathrm{B}$ & 0,75 & $8,45 \%$ & $29,23 \%$ & $24,75 \%$ & 3,5278 & 3,0987 & $-18,44 \%$ \\
\hline 57 & CV/GARCH-t & $\bar{A}$ & $\mathrm{~A}$ & $\bar{B}$ & 0,75 & $8,45 \%$ & $29,23 \%$ & $24,77 \%$ & 3,5278 & 3,1024 & $-18,40 \%$ \\
\hline 58 & FHS/GARCH-t & A & $\mathrm{A}$ & $\mathrm{B}$ & 0,75 & $8,45 \%$ & $29,23 \%$ & $24,90 \%$ & 3,5278 & 3,1156 & $-17,92 \%$ \\
\hline 59 & CV/EGARCH-N & A & A & B & 0,75 & $8,45 \%$ & $29,23 \%$ & $24,98 \%$ & 3,5278 & 3,1238 & $-17,57 \%$ \\
\hline 60 & FHS/GARCH-N & $\mathrm{A}$ & $\mathrm{A}$ & $\mathrm{B}$ & 0,75 & $8,45 \%$ & $29,23 \%$ & $24,99 \%$ & 3,5278 & 3,1249 & $-17,52 \%$ \\
\hline 61 & CV/GARCH-N & $\bar{A}$ & $\mathrm{~A}$ & $\mathrm{~B}$ & 0,75 & $8,45 \%$ & $29,23 \%$ & $25,36 \%$ & 3,5278 & 3,1643 & $-16,13 \%$ \\
\hline 62 & CV/EGARCH-t & A & A & B & 0,90 & $8,45 \%$ & $29,23 \%$ & $26,75 \%$ & 3,5278 & 3,3569 & $-12,09 \%$ \\
\hline 63 & FHS/EGARCH-t & $\mathrm{A}$ & $\mathrm{A}$ & $\mathrm{B}$ & 0,90 & $8,45 \%$ & $29,23 \%$ & $26,87 \%$ & 3,5278 & 3,3696 & $-11,62 \%$ \\
\hline 64 & FHS/EGARCH-N & $\mathrm{A}$ & $\mathrm{A}$ & $\mathrm{B}$ & 0,90 & $8,45 \%$ & $29,23 \%$ & $26,93 \%$ & 3,5278 & 3,3745 & $-11,39 \%$ \\
\hline 65 & CV/GARCH-t & $\bar{A}$ & $\mathrm{~A}$ & $\mathrm{~B}$ & 0,90 & $8,45 \%$ & $29,23 \%$ & $26,95 \%$ & 3,5278 & 3,3781 & $-11,35 \%$ \\
\hline 66 & FHS/GARCH-t & A & $\mathrm{A}$ & $\mathrm{B}$ & 0,90 & $8,45 \%$ & $29,23 \%$ & $27,07 \%$ & 3,5278 & 3,3911 & $-10,87 \%$ \\
\hline 67 & CV/EGARCH-N & A & A & B & 0,90 & $8,45 \%$ & $29,23 \%$ & $27,16 \%$ & 3,5278 & 3,3993 & $-10,52 \%$ \\
\hline 68 & FHS/GARCH-N & $\mathrm{A}$ & $\mathrm{A}$ & $\mathrm{B}$ & 0,90 & $8,45 \%$ & $29,23 \%$ & $27,17 \%$ & 3,5278 & 3,4004 & $-10,47 \%$ \\
\hline 69 & CV/GARCH-N & $\bar{A}$ & $\mathrm{~A}$ & $\bar{B}$ & 0,90 & $8,45 \%$ & $29,23 \%$ & $27,54 \%$ & 3,5278 & 3,4395 & $-9,09 \%$ \\
\hline 70 & EVT-POT & A & B & $\mathrm{B}$ & 0,75 & $8,45 \%$ & $29,23 \%$ & $27,55 \%$ & 3,5278 & 3,3436 & $-6,27 \%$ \\
\hline 71 & EVT-POT & A & $\mathrm{A}$ & $\mathrm{B}$ & 0,50 & $8,45 \%$ & $29,23 \%$ & $28,16 \%$ & 3,5278 & 3,4176 & $-4,29 \%$ \\
\hline 72 & BCBS & $\mathrm{B}$ & $\mathrm{A}$ & $\mathrm{B}$ & 0,50 & $8,45 \%$ & $29,23 \%$ & $29,84 \%$ & 3,5278 & 3,6004 & $1,94 \%$ \\
\hline 73 & EVT-POT & A & $\mathrm{A}$ & $\mathrm{B}$ & 0,75 & $8,45 \%$ & $29,23 \%$ & $30,70 \%$ & 3,5278 & 3,7387 & $3,92 \%$ \\
\hline 74 & BCBS & $\mathrm{B}$ & A & $\mathrm{B}$ & 0,75 & $8,45 \%$ & $29,23 \%$ & $32,33 \%$ & 3,5278 & 3,9159 & $10,01 \%$ \\
\hline 75 & EVT-POT & $\mathrm{A}$ & A & $\mathrm{B}$ & 0,90 & $8,45 \%$ & $29,23 \%$ & $32,81 \%$ & 3,5278 & 4,0058 & $10,75 \%$ \\
\hline 76 & BCBS & $\mathrm{B}$ & $\mathrm{A}$ & $\mathrm{B}$ & 0,90 & $8,45 \%$ & $29,23 \%$ & $34,41 \%$ & 3,5278 & 4,1792 & $16,74 \%$ \\
\hline
\end{tabular}

Note: the following abbreviations apply:

A

B

FHS

$\mathrm{CV}$

GARCH

EGARCH

$\mathrm{N}$

$\mathrm{t}$

EVT-POT
: Alternative solution, i.e., the fixed BCBS parameter is changed

: BCBS's parameter

: Filtered Historical Simulation

: Conditional Volatility

: General Autoregressive Conditional Heteroscedasticity Model

: Exponential GARCH

: Normal distribution

: Student-t distribution

: Extreme Value Theory via Peaks-Over-Threshold after GARCH-N pre-whitening Source: Own elaboration 
Table 6. Results of the simulation analysis - US

\begin{tabular}{|c|c|c|c|c|c|c|c|c|c|c|c|}
\hline $\begin{array}{l}\text { Case } \\
\mathrm{N}^{\circ} \\
{[1]}\end{array}$ & $\begin{array}{c}\text { Risk Weight } \\
\text { Model } \\
\text { [2] }\end{array}$ & $\begin{array}{l}\text { SA } \\
\text { RW } \\
{[3]}\end{array}$ & $\begin{array}{c}\text { SA } \\
\rho \\
{[4]}\end{array}$ & $\begin{array}{l}\text { SA } \\
\gamma \\
{[5]}\end{array}$ & $\begin{array}{c}\text { SA } \\
P \\
{[6]}\end{array}$ & $\begin{array}{c}\text { Max. } \\
\text { Loss } \\
{[7]}\end{array}$ & $\begin{array}{c}\text { ERC } \\
\text { SA(B) } \\
{[8]}\end{array}$ & $\begin{array}{c}\text { ERC } \\
\text { SA(A) } \\
{[9]}\end{array}$ & $\begin{array}{c}\text { LCR } \\
\text { SA(B) } \\
{[10]}\end{array}$ & $\begin{array}{c}\text { LCR } \\
\text { SA(A) } \\
{[11]}\end{array}$ & $\begin{array}{l}\text { LCR } \\
\text { Var. } \\
\text { [12] }\end{array}$ \\
\hline 1 & CV/EGARCH-t & $\mathrm{A}$ & $\mathrm{B}$ & $\mathrm{B}$ & 0,75 & $10,50 \%$ & $30,62 \%$ & $28,16 \%$ & 3,6493 & 2,7122 & $-8,17 \%$ \\
\hline 2 & FHS/EGARCH-t & A & B & B & 0,75 & $10,50 \%$ & $30,62 \%$ & $28,18 \%$ & & 2,7141 & $-8,10 \%$ \\
\hline 3 & HS/GARCH-t & A & B & B & 0,75 & $10,50 \%$ & $30,62 \%$ & $28,20 \%$ & & & \\
\hline 4 & & $\mathrm{~A}$ & $\mathrm{~B}$ & $\mathrm{~B}$ & 0,75 & & & & & & \\
\hline 5 & & A & B & B & & & & $28,20 \%$ & & & \\
\hline 6 & / / GAK & $\mathrm{A}$ & B & B & & & & & & & \\
\hline 7 & $\mathrm{HS} / \mathrm{EGA}$ & A & B & B & 0,75 & $10,50 \%$ & $30,62 \%$ & $28,21 \%$ & 3,6493 & 2,7174 & $-7,99 \%$ \\
\hline 8 & /GARC & $\mathrm{A}$ & B & B & 0,75 & $10,50 \%$ & $30,62 \%$ & $28,22 \%$ & 3,6493 & 2,7178 & $-7,97 \%$ \\
\hline 9 & I/EGAF & A & B & A & 0,75 & $10,50 \%$ & $30,62 \%$ & $28,49 \%$ & 3,6493 & 2,7443 & $-7,06 \%$ \\
\hline 10 & H-t & $\mathrm{A}$ & B & $\mathrm{A}$ & 0,75 & $10,50 \%$ & $30,62 \%$ & $28,56 \%$ & 3,64 & 2,7513 & $-6,82 \%$ \\
\hline 11 & $\frac{1}{T T-}$ & A & B & B & 0,75 & $10,50 \%$ & $30,62 \%$ & $28,60 \%$ & 3,6493 & 3,4031 & $-6,72 \%$ \\
\hline 12 & RCH-t & $\mathrm{A}$ & $\mathrm{B}$ & $\mathrm{A}$ & 0,75 & $10,50 \%$ & $30,62 \%$ & $28,62 \%$ & 3,64 & & $-6,63 \%$ \\
\hline 13 & $\mathrm{H}-\mathrm{N}$ & $\mathrm{A}$ & $\mathrm{B}$ & $\mathrm{A}$ & 0,75 & $10,50 \%$ & $30,62 \%$ & $28,63 \%$ & 3,6493 & & $-6,61 \%$ \\
\hline 14 & HS/GAR & $\mathrm{A}$ & $\mathrm{B}$ & A & 0,75 & $10,50 \%$ & $30,62 \%$ & $28,65 \%$ & 3,6493 & & $-6,55 \%$ \\
\hline 15 & $\mathrm{~V} / \mathrm{GAI}$ & A & B & A & 0,75 & $10,50 \%$ & $30,62 \%$ & $28,65 \%$ & 3,6493 & & $-6,54 \%$ \\
\hline 16 & $\mathrm{CH}-\mathrm{N}$ & $\mathrm{A}$ & B & A & 0,75 & $10,50 \%$ & $30,62 \%$ & $28,69 \%$ & 3,6493 & & $-6,40 \%$ \\
\hline 17 & $\mathrm{~V} / \mathrm{G}$ & A & B & A & 0,75 & $10,50 \%$ & $30,62 \%$ & $28,71 \%$ & 3,6493 & & $-6,35 \%$ \\
\hline 18 & VT-P & A & B & A & 0,75 & $10,50 \%$ & $30,62 \%$ & $30,01 \%$ & 3,6493 & 2,8892 & $-2,04 \%$ \\
\hline 19 & RCH-t & $\mathrm{A}$ & A & $\mathrm{B}$ & 0,50 & $10,50 \%$ & $30,62 \%$ & $36,50 \%$ & 3,6493 & & $18,99 \%$ \\
\hline 20 & H-t & $\mathrm{A}$ & A & B & 0,50 & $10,50 \%$ & $30,62 \%$ & $36,51 \%$ & & & \\
\hline 21 & & $\mathrm{~A}$ & $\bar{A}$ & $\mathrm{~B}$ & 0,50 & 10,5 & & $36,52 \%$ & & & \\
\hline 22 & & A & A & B & 0,50 & & & $36,53 \%$ & & & \\
\hline 23 & & $\mathrm{~A}$ & A & B & & & & $36,53 \%$ & & & \\
\hline 24 & & A & A & B & & & & & & & \\
\hline 25 & & & A & B & & & & & & & \\
\hline 26 & & $\mathrm{~A}$ & $\mathrm{~A}$ & B & & & & & & & \\
\hline 27 & & B & B & A & 0,75 & & & & & & \\
\hline 28 & & A & $\mathrm{A}$ & $\mathrm{A}$ & 0,50 & & & 36,7 & & & \\
\hline 29 & & A & $\mathrm{A}$ & $\mathrm{A}$ & 0,50 & & 30 , & $36,81 \%$ & & & $20,03 \%$ \\
\hline 30 & & $\mathrm{~A}$ & $\mathrm{~A}$ & B & 0,50 & 10 , & $30,62 \%$ & $36,83 \%$ & 3,6 & & $20,12 \%$ \\
\hline 31 & & $\mathrm{~A}$ & $\mathrm{~A}$ & $\mathrm{~A}$ & 0,50 & $0 \%$ & $52 \%$ & $36,85 \%$ & 3,6 & & $20,18 \%$ \\
\hline 32 & & A & $\mathrm{A}$ & $\mathrm{A}$ & 0,50 & $10,50 \%$ & $30,62 \%$ & $36,86 \%$ & 3,6493 & 3,5526 & $20,20 \%$ \\
\hline 33 & $\mathrm{H}-\mathrm{N}$ & $\mathrm{A}$ & $\mathrm{A}$ & $\mathrm{A}$ & 0,50 & $10,50 \%$ & $30,62 \%$ & $36,87 \%$ & 3,6493 & 3,5539 & $20,24 \%$ \\
\hline 34 & & A & A & A & 0,50 & $10,50 \%$ & $30,62 \%$ & $36,87 \%$ & 3,6493 & 3,5542 & $20,25 \%$ \\
\hline 35 & 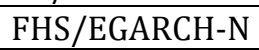 & $\mathrm{A}$ & A & A & 0,50 & $10,50 \%$ & $30,62 \%$ & $36,91 \%$ & 3,6493 & 3,5572 & $20,36 \%$ \\
\hline 36 & & A & A & A & 0,50 & $10,50 \%$ & $30,62 \%$ & $36,92 \%$ & & & $20,40 \%$ \\
\hline 37 & VT & A & A & A & 0,50 & $10,50 \%$ & $30,62 \%$ & $37,94 \%$ & 3,6493 & 3,6560 & $23,79 \%$ \\
\hline 38 & & A & A & B & 0,75 & $10,50 \%$ & $30,62 \%$ & $38,40 \%$ & 3,6493 & 3,7005 & $25,17 \%$ \\
\hline 39 & $\mathrm{H}-\mathrm{t}$ & $\mathrm{A}$ & A & $\mathrm{B}$ & 0,75 & $10,50 \%$ & $30,62 \%$ & $38,41 \%$ & 3,6493 & 3,7019 & $25,22 \%$ \\
\hline 40 & & A & A & B & 0,75 & $10,50 \%$ & $30,62 \%$ & $38,43 \%$ & & 3,7032 & $25,27 \%$ \\
\hline 41 & & $\mathrm{~A}$ & $\bar{A}$ & B & 0,75 & & & $38,43 \%$ & & & $25,28 \%$ \\
\hline 42 & & A & A & B & & & & & & & $25,28 \%$ \\
\hline 43 & & A & $\mathrm{A}$ & B & 0,75 & & & $38,43 \%$ & & & $25,28 \%$ \\
\hline 44 & & $\mathrm{~A}$ & A & B & 0,75 & & & & & & $25,31 \%$ \\
\hline 45 & & $\mathrm{~A}$ & $\mathrm{~A}$ & B & 0,75 & & & & & & $25,32 \%$ \\
\hline 46 & BCBS & B & $\mathrm{A}$ & B & 0,50 & $10,50 \%$ & $30,62 \%$ & $38,43 \%$ & 3,6493 & 3,7033 & $25,41 \%$ \\
\hline
\end{tabular}




\begin{tabular}{|c|c|c|c|c|c|c|c|c|c|c|c|}
\hline 47 & CV/EGARCH-t & A & A & A & 0,75 & $10,50 \%$ & $30,62 \%$ & $38,64 \%$ & 3,6493 & 3,7242 & $25,99 \%$ \\
\hline 48 & FHS/EGARCH-t & $\mathrm{A}$ & $\mathrm{A}$ & $\mathrm{A}$ & 0,75 & $10,50 \%$ & $30,62 \%$ & $38,70 \%$ & 3,6493 & 3,7293 & $26,16 \%$ \\
\hline 49 & EVT-POT & $\mathrm{A}$ & $\mathrm{A}$ & $\mathrm{B}$ & 0,75 & $10,50 \%$ & $30,62 \%$ & $38,72 \%$ & 3,6493 & 3,7314 & $26,24 \%$ \\
\hline 50 & FHS/GARCH-t & $\mathrm{A}$ & $\mathrm{A}$ & $\mathrm{A}$ & 0,75 & $10,50 \%$ & $30,62 \%$ & $38,74 \%$ & 3,6493 & 3,7336 & $26,31 \%$ \\
\hline 51 & CV/EGARCH-N & $\mathrm{A}$ & $\mathrm{A}$ & A & 0,75 & $10,50 \%$ & $30,62 \%$ & $38,74 \%$ & 3,6493 & 3,7340 & $26,32 \%$ \\
\hline 52 & FHS/GARCH-N & A & A & A & 0,75 & $10,50 \%$ & $30,62 \%$ & $38,76 \%$ & 3,6493 & 3,7352 & $26,37 \%$ \\
\hline 53 & CV/GARCH-t & A & A & A & 0,75 & $10,50 \%$ & $30,62 \%$ & $38,76 \%$ & 3,6493 & 3,7355 & $26,37 \%$ \\
\hline 54 & FHS/EGARCH-N & A & A & A & 0,75 & $10,50 \%$ & $30,62 \%$ & $38,79 \%$ & 3,6493 & 3,7384 & $26,48 \%$ \\
\hline 55 & CV/GARCH-N & A & A & A & 0,75 & $10,50 \%$ & $30,62 \%$ & $38,80 \%$ & 3,6493 & 3,7394 & $26,51 \%$ \\
\hline 56 & EVT-POT & A & A & A & 0,75 & $10,50 \%$ & $30,62 \%$ & $39,78 \%$ & 3,6493 & 3,8325 & $29,75 \%$ \\
\hline 57 & $\mathrm{CV} / \mathrm{EGARCH}-\mathrm{t}$ & A & A & B & 0,90 & $10,50 \%$ & $30,62 \%$ & $39,86 \%$ & 3,6493 & 3,8410 & $29,95 \%$ \\
\hline 58 & FHS/EGARCH-t & $\mathrm{A}$ & $\mathrm{A}$ & $\mathrm{B}$ & 0,90 & $10,50 \%$ & $30,62 \%$ & $39,88 \%$ & 3,6493 & 3,8424 & $30,00 \%$ \\
\hline 59 & FHS/GARCH-t & $\mathrm{A}$ & $\mathrm{A}$ & $\mathrm{B}$ & 0,90 & $10,50 \%$ & $30,62 \%$ & $39,89 \%$ & 3,6493 & 3,8436 & $30,04 \%$ \\
\hline 60 & FHS/GARCH-N & $\mathrm{A}$ & $\mathrm{A}$ & $\mathrm{B}$ & 0,90 & $10,50 \%$ & $30,62 \%$ & $39,89 \%$ & 3,6493 & 3,8439 & $30,05 \%$ \\
\hline 61 & CV/EGARCH-N & $\mathrm{A}$ & $\mathrm{A}$ & $\mathrm{B}$ & 0,90 & $10,50 \%$ & $30,62 \%$ & $39,90 \%$ & 3,6493 & 3,8440 & $30,06 \%$ \\
\hline 62 & CV/GARCH-t & $\mathrm{A}$ & $\mathrm{A}$ & $\mathrm{B}$ & 0,90 & $10,50 \%$ & $30,62 \%$ & $39,90 \%$ & 3,6493 & 3,8441 & $30,06 \%$ \\
\hline 63 & FHS/EGARCH-N & $\mathrm{A}$ & $\mathrm{A}$ & $\mathrm{B}$ & 0,90 & $10,50 \%$ & $30,62 \%$ & $39,90 \%$ & 3,6493 & 3,8447 & $30,08 \%$ \\
\hline 64 & CV/GARCH-N & $\mathrm{A}$ & $\mathrm{A}$ & $\mathrm{B}$ & 0,90 & $10,50 \%$ & $30,62 \%$ & $39,91 \%$ & 3,6493 & 3,8450 & $30,09 \%$ \\
\hline 65 & EVT-POT & $\mathrm{A}$ & $\mathrm{A}$ & $\mathrm{B}$ & 0,90 & $10,50 \%$ & $30,62 \%$ & $40,17 \%$ & 3,6493 & 3,8708 & $30,98 \%$ \\
\hline 66 & FHS/EGARCH-N & $\mathrm{A}$ & $\mathrm{A}$ & $\mathrm{A}$ & 0,90 & $10,50 \%$ & $30,62 \%$ & $40,20 \%$ & 2,9487 & 3,8736 & $31,08 \%$ \\
\hline 67 & FHS/EGARCH-t & A & A & A & 0,90 & $10,50 \%$ & $30,62 \%$ & $40,24 \%$ & 2,9487 & 3,8770 & $31,20 \%$ \\
\hline 68 & CV/EGARCH-t & $\mathrm{A}$ & $\mathrm{A}$ & $\mathrm{A}$ & 0,90 & $10,50 \%$ & $30,62 \%$ & $40,24 \%$ & 2,9487 & 3,8774 & $31,22 \%$ \\
\hline 69 & FHS/GARCH-t & $\mathrm{A}$ & $\mathrm{A}$ & $\mathrm{A}$ & 0,90 & $10,50 \%$ & $30,62 \%$ & $40,25 \%$ & 2,9487 & 3,8784 & $31,25 \%$ \\
\hline 70 & FHS/GARCH-N & $\mathrm{A}$ & $\mathrm{A}$ & $\mathrm{A}$ & 0,90 & $10,50 \%$ & $30,62 \%$ & $40,27 \%$ & 2,9487 & 3,8799 & $31,30 \%$ \\
\hline 71 & CV/EGARCH-N & $\mathrm{A}$ & $\mathrm{A}$ & $\mathrm{A}$ & 0,90 & $10,50 \%$ & $30,62 \%$ & $40,34 \%$ & 2,9487 & 3,8863 & $31,52 \%$ \\
\hline 72 & CV/GARCH-t & $\mathrm{A}$ & $\mathrm{A}$ & $\mathrm{A}$ & 0,90 & $10,50 \%$ & $30,62 \%$ & $40,34 \%$ & 2,9487 & 3,8868 & $31,54 \%$ \\
\hline 73 & CV/GARCH-N & $\mathrm{A}$ & $\mathrm{A}$ & $\mathrm{A}$ & 0,90 & $10,50 \%$ & $30,62 \%$ & $40,40 \%$ & 2,9487 & 3,8925 & $31,74 \%$ \\
\hline 74 & EVT-POT & A & A & A & 0,90 & $10,50 \%$ & $30,62 \%$ & $41,55 \%$ & 2,9487 & 4,0027 & $35,55 \%$ \\
\hline 75 & BCBS & B & A & $\mathrm{B}$ & 0,90 & $10,50 \%$ & $30,62 \%$ & $41,65 \%$ & 3,6493 & 4,0121 & $35,86 \%$ \\
\hline 76 & BCBS & $\mathrm{B}$ & A & $\mathrm{B}$ & 0,75 & $10,50 \%$ & $30,62 \%$ & $44,89 \%$ & 3,6493 & 4,3219 & $46,67 \%$ \\
\hline
\end{tabular}

Note: the following abbreviations apply:

A

B

FHS

CV

GARCH

EGARCH

$\mathrm{N}$

$\mathrm{t}$

EVT-POT

: Alternative solution, i.e., the fixed BCBS parameter is changed

: BCBS's parameter

: Filtered Historical Simulation

: Conditional Volatility

: General Autoregressive Conditional Heteroscedasticity Model

: Exponential GARCH

: Normal distribution

: Student-t distribution

: Extreme Value Theory via Peaks-Over-Threshold after GARCH-N pre-whitening Source: Own elaboration

Table 7. Calibration parameter sa - UK

\begin{tabular}{|c|c|c|c|c|}
\hline $\begin{array}{c}\text { Case } \\
\text { Number }\end{array}$ & $\begin{array}{c}\text { Loss Coverage } \\
\text { Ratio } \\
\text { LCR }\end{array}$ & $\begin{array}{c}\text { Maximum } \\
\text { Loss }\end{array}$ & $\begin{array}{c}\text { Equity Risk } \\
\text { Capital } \\
\text { SA } \\
\text { BCBS version } \\
{[4]}\end{array}$ & $\begin{array}{c}\text { sa } \\
\text { calibration } \\
\text { parameter }\end{array}$ \\
\hline [1] & {$[2]$} & {$[3]$} & $29,23 \%$ & {$[5]$} \\
\hline 1 & 1,00 & $-8,45 \%$ & $28,23 \%$ & $31,79 \%$ \\
\hline 2 & 1,10 & $-8,45 \%$ & $29,23 \%$ & $34,68 \%$ \\
\hline 3 & 1,20 & $-8,45 \%$ & \multicolumn{2}{|c}{} \\
\hline
\end{tabular}


REMEF (The Mexican Journal of Economics and Finance)

The New Standardised Approach as a Credible Fallback

\begin{tabular}{|c|c|c|c|c|}
\hline 4 & 1,30 & $-8,45 \%$ & $29,23 \%$ & $37,57 \%$ \\
\hline 5 & 1,40 & $-8,45 \%$ & $29,23 \%$ & $40,46 \%$ \\
\hline 6 & 1,50 & $-8,45 \%$ & $29,23 \%$ & $43,35 \%$ \\
\hline 7 & 1,60 & $-8,45 \%$ & $29,23 \%$ & $46,25 \%$ \\
\hline 8 & 1,70 & $-8,45 \%$ & $29,23 \%$ & $49,14 \%$ \\
\hline 9 & 1,80 & $-8,45 \%$ & $29,23 \%$ & $52,03 \%$ \\
\hline 10 & 1,90 & $-8,45 \%$ & $29,23 \%$ & $54,92 \%$ \\
\hline 11 & 2,00 & $-8,45 \%$ & $29,23 \%$ & $57,81 \%$ \\
\hline 12 & 2,10 & $-8,45 \%$ & $29,23 \%$ & $60,70 \%$ \\
\hline 13 & 2,20 & $-8,45 \%$ & $29,23 \%$ & $63,59 \%$ \\
\hline 14 & 2,30 & $-8,45 \%$ & $29,23 \%$ & $66,48 \%$ \\
\hline 15 & 2,40 & $-8,45 \%$ & $29,23 \%$ & $69,37 \%$ \\
\hline 16 & 2,50 & $-8,45 \%$ & $29,23 \%$ & $72,26 \%$ \\
\hline 17 & 2,60 & $-8,45 \%$ & $29,23 \%$ & $75,15 \%$ \\
\hline 18 & 2,70 & $-8,45 \%$ & $29,23 \%$ & $78,04 \%$ \\
\hline 19 & 2,80 & $-8,45 \%$ & $29,23 \%$ & $80,93 \%$ \\
\hline 20 & 2,90 & $-8,45 \%$ & $29,23 \%$ & $83,82 \%$ \\
\hline 21 & 3,00 & $-8,45 \%$ & $29,23 \%$ & $86,71 \%$ \\
\hline 22 & 3,10 & $-8,45 \%$ & $29,23 \%$ & $89,60 \%$ \\
\hline 23 & 3,20 & $-8,45 \%$ & $29,23 \%$ & $92,49 \%$ \\
\hline 24 & 3,30 & $-8,45 \%$ & $29,23 \%$ & $95,38 \%$ \\
\hline 25 & 3,40 & $-8,45 \%$ & $29,23 \%$ & $98,27 \%$ \\
\hline 26 & 3,50 & $-8,45 \%$ & $29,23 \%$ & $101,16 \%$ \\
\hline 27 & 3,60 & $-8,45 \%$ & $29,23 \%$ & $104,05 \%$ \\
\hline 28 & 3,70 & $-8,45 \%$ & $29,23 \%$ & $106,94 \%$ \\
\hline 29 & 3,80 & $-8,45 \%$ & $29,23 \%$ & $109,83 \%$ \\
\hline 30 & 3,90 & $-8,45 \%$ & $29,23 \%$ & $112,72 \%$ \\
\hline 31 & 4,00 & $-8,45 \%$ & $29,23 \%$ & $115,61 \%$ \\
\hline
\end{tabular}

Source: Own elaboration

Table 8. Calibration parameter sa - US

\begin{tabular}{|c|c|c|c|c|}
\hline $\begin{array}{c}\text { Case } \\
\text { Number }\end{array}$ & $\begin{array}{c}\text { Loss Coverage } \\
\text { Ratio } \\
\text { LCR }\end{array}$ & $\begin{array}{c}\text { Maximum } \\
\text { Loss }\end{array}$ & $\begin{array}{c}\text { Equity Risk } \\
\text { Capital } \\
\text { SA } \\
\text { BCBS version } \\
\text { [4] }\end{array}$ & $\begin{array}{c}\text { sa } \\
\text { calibration } \\
\text { parameter }\end{array}$ \\
\hline$[\mathbf{1}]$ & {$[\mathbf{2}]$} & {$[\mathbf{3}]$} & $30,62 \%$ & [5] \\
\hline 1 & 1,00 & $-10,50 \%$ & $30,62 \%$ & $34,29 \%$ \\
\hline 2 & 1,10 & $-10,50 \%$ & $30,62 \%$ & $41,72 \%$ \\
\hline 3 & 1,20 & $-10,50 \%$ & $30,62 \%$ & $44,58 \%$ \\
\hline 4 & 1,30 & $-10,50 \%$ & $30,62 \%$ & $48,01 \%$ \\
\hline 5 & 1,40 & $-10,50 \%$ & $30,62 \%$ & $51,43 \%$ \\
\hline 6 & 1,50 & $-10,50 \%$ & $30,62 \%$ & $54,86 \%$ \\
\hline 7 & 1,60 & $-10,50 \%$ & $30,62 \%$ & $58,29 \%$ \\
\hline 8 & 1,70 & $-10,50 \%$ & $30,62 \%$ & $61,72 \%$ \\
\hline 9 & 1,80 & $-10,50 \%$ & $30,62 \%$ & $65,15 \%$ \\
\hline 10 & 1,90 & $-10,50 \%$ & $30,62 \%$ & $68,58 \%$ \\
\hline 11 & 2,00 & $-10,50 \%$ & $30,62 \%$ & $72,01 \%$ \\
\hline 12 & 2,10 & $-10,50 \%$ & $30,62 \%$ & $75,44 \%$ \\
\hline 13 & 2,20 & $-10,50 \%$ & $30,62 \%$ & $78,87 \%$ \\
\hline 14 & 2,30 & $-10,50 \%$ & &
\end{tabular}




\begin{tabular}{|l|l|l|l|l|}
\hline 15 & 2,40 & $-10,50 \%$ & $30,62 \%$ & $82,30 \%$ \\
\hline 16 & 2,50 & $-10,50 \%$ & $30,62 \%$ & $85,72 \%$ \\
\hline 17 & 2,60 & $-10,50 \%$ & $30,62 \%$ & $89,15 \%$ \\
\hline 18 & 2,70 & $-10,50 \%$ & $30,62 \%$ & $92,58 \%$ \\
\hline 19 & 2,80 & $-10,50 \%$ & $30,62 \%$ & $96,01 \%$ \\
\hline 20 & 2,90 & $-10,50 \%$ & $30,62 \%$ & $99,44 \%$ \\
\hline 21 & 3,00 & $-10,50 \%$ & $30,62 \%$ & $102,87 \%$ \\
\hline 22 & 3,10 & $-10,50 \%$ & $30,62 \%$ & $106,30 \%$ \\
\hline 23 & 3,20 & $-10,50 \%$ & $30,62 \%$ & $109,73 \%$ \\
\hline 24 & 3,30 & $-10,50 \%$ & $30,62 \%$ & $113,16 \%$ \\
\hline 25 & 3,40 & $-10,50 \%$ & $30,62 \%$ & $116,59 \%$ \\
\hline 26 & 3,50 & $-10,50 \%$ & $30,62 \%$ & $120,01 \%$ \\
\hline 27 & 3,60 & $-10,50 \%$ & $30,62 \%$ & $123,44 \%$ \\
\hline 28 & 3,70 & $-10,50 \%$ & $30,62 \%$ & $126,87 \%$ \\
\hline 29 & 3,80 & $-10,50 \%$ & $30,62 \%$ & $130,30 \%$ \\
\hline 30 & 3,90 & $-10,50 \%$ & $30,62 \%$ & $133,73 \%$ \\
\hline 31 & 4,00 & $-10,50 \%$ & $30,62 \%$ & $137,16 \%$ \\
\hline
\end{tabular}

Source: Own elaboration

\section{Conclusion}

In 2013 the BCBS established a series of key areas to focus on in the transcendental review of the market risk framework, among which the replacement of VaR (and sVaR) for ES as the new risk metric and the radical overhaul of the SA in order to turn it into a more risk sensitive methodology. While in perspective its intentions were healthy, the present study points out many relevant issues that could potentially dent its effectiveness or eventually derail the whole plot, thus leaving unresolved the issues intended to be remedied.

Although the SA has been, by all means, significantly improved and transformed in a kind of risk-oriented scheme, it still appears relatively inflexible in consideration of the fixed values present in the formulation, namely $R W$ and the correlation parameters within and between the risk buckets: $\rho$ and $\gamma$ respectively. Given the empirical nature of the work encompassed, the issue seems, at least, a very contentious one notwithstanding which some evidence allow to somewhat disentangle the mechanics of SA. It is important to bear in mind, as the study suggests, that the 'universal recipe' comprised in Basel IV could not be applicable to every country, and, furthermore, the separation between 'developed' and 'emerging' economies and the arbitrary classification of risk buckets can backfire on the intended objectives of the reform.

The study identifies $R W$ as the variable that weighs the most throughout the formulae. The figures evince that the adoption of the official prescription appears very polemical, with potential adverse effects on $E R C$ in view of the huge quantity of representations capable of delivering a wide variety of outcomes. A highly leptokurtic technique like EVT-POT surges as the best approximation to SA's configuration, with the rest of the specifications following suit, thus hinting at the rationale in BCBS's mind when enacting SA. The remaining parameters do not appear as materially relevant for $E R C$ calculation as the previous one and might be used to fine-tune the final outcome by, for instance, altering the samples over which they are measured.

The whole exercise, with its multiplicity of variables, could in principle point to the fact that BCBS's SA yields somewhat excessive capital levels. In effect, bringing the LCR into play, it may be 
observed that the official SA gives very substantial coverage (in excess of 3.50), probably immobilising resources that could be applied to more productive uses, this way enhancing the potential for profits. The research proposes to grant the national regulators with more leeway when implementing the SA and alter the foundations (most importantly the $R W$ ) by authorising the utilisation of the techniques that best suits the markets and assets in question: in this vein, highly volatile scenarios would require leptokurtic models like EVT-POT, whilst more 'tranquil' ones would end unnecessarily penalised and could opt for other systems, such as those representations rooting in Conditional Volatility or Filtered Historical Simulation provided they comply with some quantitative requirements. Alternatively, the correlation parameters within and between buckets might be changed regarding the needs of the watchdog, but, so far, and acknowledging the necessity of more research, their effects would prove more diffused. According to the outcome of the study, they might be employed to adjust the main outcome.

Were some national regulators to stick to the BCBS's formulae (for whatever reasons), it would be advisable to resort to the $L C R$ to assess the adequacy of the capital levels obtained. In this vein, supervisors should target a specific $L C R$ and calibrate the resulting $E R C$ derived from BCBS's by means of the adjustment parameter sa to be introduced in the SA calculation.

The above considerations are deemed very important in consideration of one of the declared aims of Basel IV, i.e., the coordination of SA and IMA duality. Delving into the fabrics of the new dispositions, and bearing in mind the outcome of the SA exercise, the evidence covertly suggest that the BCBS intends to crack down on internal risk modelling, both for credit and market risk as well ${ }^{9}$. Furthermore, the BCBS designed SA in such a manner that it supersedes the IMA by providing input floors' and 'output floors' in the shape of levels for risk parameters and base numbers that come into effect if banks' own calculations of capital produce answers below SA's respectively.

However, the new SA could prove potentially useful in view of the Covid-19 crisis, given that, as McSheaffrey et. al. (2020) point out, the IMA may distort fair valuations, and the increase in market volatility might constitute a stress scenario for stochastic volatility models and their adjustment and, more specifically, the stressed period window (either for Basel III or Basel IV configurations) could end up in need of reassessment. Baret et.al. (2020) underline that markets seem to be pricing using worst-case scenarios which translate into higher capital levels as a result of the higher volatility and counterparty risk. Accordingly, many banks have also requested that regulators ease capital requirements, in a move that many experts brand as "opportunistic" (Merle (2020)). The authors, furthermore, emphasise the possibility of liquidity tightening which appears to be overlooked by the newly enacted SA.

Gobbo (2020) adequately sythesises the reasons behind the increase in market risk capital requirements, enumerating the heightened noise in market data, dispersion of spreads, swollen market volatility across all asset classes, limit breaches, backtesting outliers and elevated risk measures. These, in turn, might lead to financial losses from credit and fair valuation adjustments and recommends a redesign of the frameworks in the light of procyclical risk measures like VaR.

\footnotetext{
${ }^{9}$ Wallace, 2017, synthetises that course of action stating that “...Basel IV reforms aim to contain and constrain the use of internal models".
} 
All things considered, the present Covid 19 accentuates the relevance of the overhauled SA and the benefits to work in anticipation to its enactment. With the data at hand, the SA would deliver unquestionably high 'output floors', hence questions referred to the usefulness of IMA and the disincentives for accuracy hover in the background. Not only does the SA not appear to fulfill its function as a 'credible fall-back' to IMA, but it may endanger the financial health of the banks blocking the credit channel and the ensuing profit potential as well. Therefore, it is imperative to work on the flexibility of the SA, either modifying the rigid parameters or introducing calibration factors, with a view to obtaining precise capital levels, encouraging the application of sound IMA and, simultaneously, keeping an eye on the stability of the financial system.

\section{References}

[1] Acerbi, C., and Tasche D., (2002), On the Coherence of Expected Shortfall, Journal of Banking and Finance 26, pp. 1487-1503. https://doi.org/10.1016/s0378-4266(02)00283-2

[2] Alexander, C., (2008), Market Risk Analysis Volume IV: Value-at-Risk Models, John Wiley \& Sons Ltd., The Atrium, Southern Gate, Chichester, West Sussex, United Kingdom.

[3] Artzner, J., Delbaen, F., Eber, K., and Heath D., (1999), Coherent Measures of Risk, Mathematical Finance, Vol. 9, No. 3, pp. 203-228. https://doi.org/10.1111/1467-9965.00068

[4] Baret, S., Celner, A., O'reilly, M. and Shilling, M., (2020), COVID-19 potential implications for the banking and capital markets sector. Maintaining business and operational resilience, Deloittte Center for Financial Services, Deloitte Touche Tonmatsu Limited, United Kingdom. Available at: https://www2.deloitte.com/content/dam/insights/us/articles/6693_covid-19-banking/DI_COVID19-banking.pdf

[5] Barone-Adesi, G., F. Bourgoin, and K. Giannakopoulos, (1998), Don't look back, Risk 11, pp. 100-103.

[6] BASEL COMMITTEE ON BANKING SUPERVISION, (2006), International Convergence of Capital Measurement and Capital Standards. A Revised Framework. Comprehensive version, Bank for International Settlements, Basel, Switzerland.

[7] BASEL COMMITTEE ON BANKING SUPERVISION, (2009), Strengthening the Resilience of the Banking Sector, Bank for International Settlements, Basel, Switzerland.

[8] BASEL COMMITTEE ON BANKING SUPERVISION, (2011a), Messages from the Academic Literature on Risk Measurement in the Trading Book, Working Paper No. 19, Bank for International Settlements, Basel, Switzerland.

[9] BASEL COMMITTEE ON BANKING SUPERVISION, (2011b), Revisions to the Basel II Market Risk Framework. Updated as of 31 December 2010, Bank for International Settlements, Basel, Switzerland.

[10] BASEL COMMITTEE ON BANKING SUPERVISION, (2012), Fundamental Review of the Trading Book, Bank for International Settlements, Basel, Switzerland.

[11] BASEL COMMITTEE ON BANKING SUPERVISION, (2013), Fundamental Review of the Trading Book: A Revised Market Risk Framework, Consultative Document Issued for comment by 31 January 2014, Bank for International Settlements, Basel, Switzerland.

[12] BASEL COMMITTEE ON BANKING SUPERVISION, (2014), Fundamental Review of the Trading Book: Outstanding Issues, Consultative Document Issued for comment by 20 February 2015, Bank for International Settlements, Basel, Switzerland.

[13] BASEL COMMITTEE ON BANKING SUPERVISION, (2016), Standards. Minimum Capital Requirements for market risk, January 2016, Basel, Switzerland. 
REMEF (The Mexican Journal of Economics and Finance)

The New Standardised Approach as a Credible Fallback

[14] Bollerslev, T., (1986), Generalized Autoregressive Conditional Heteroskedasticity, Journal of Econometrics, 31, pp. 307-327. https://doi.org/10.1016/0304-4076(86)90063-1

[15] Boudoukh, J., M. Richardson and R. Whitelaw, (1998), The Best of Both Worlds: A Hybrid Approach to Calculating Value-at-Risk, (1998), Risk, Vol. 11, No. 5, pp. 64-67. https://doi.org/10.2139/ssrn.51420

[16] Christoffersen, P., (2003), Elements of Financial Risk Management, Academic Press, New York, United States.

[17] Coles, S., (2001), An Introduction to Statistical Modeling of Extreme Values, Springer Series in Statistics, Springer Verlag, London, United Kingdom.

[18] Da Silva, B. and B. A.. De Melo Mendes, (2003), Value-at-Risk and Extreme Returns in the Asian Stock Markets, International Journal of Business, Vol. 8, No. 1, pp. 17-40. https://doi.org/10.2139/ssrn.420266

[19] Danielsson, J., (2002), The Emperor has No Clothes: Limits to Risk Modelling, Journal of Banking and Finance, Vol. 26, pp. 1273-1296. https://doi.org/10.1002/ana.24603

[20] DANIELSSON, J., and ZIGRAND, P., (2006), On Time-Scaling of Risk and the Square-Root of Time Rule, Journal of Banking and Finance, Vol. 30, pp. 2701-2713. https://doi.org/10.2139/ssrn.567123

[21] DELOITTE UK, (2015), Basel: The Next Generation. What is the future for internal regulatory capital models?, London, United Kingdom. Available at: https://www2.deloitte.com/content/dam/Deloitte/uk/Documents/financial-services/deloitte-ukbasel-the-next-generation-0615.pdf

[22] Embrechts, P., Klüppelberg, C., Mikosch, T., (1997). Modelling Extremal Events for Insurance and Finance, Springer-Verlag, Berlin Heidelberg, Berlin, Germany.

[23] Engle, R. F., (1982), Autoregressive Conditional Heteroskedasticity with Estimates of the Variance of the United Kingdom Inflation, Econometrica, Vol. 50, No. 4, pp. 987-1007. https://doi.org/10.2307/1912773

[24] FINGER, C., (2006), How Historical Simulation made me lazy, in April 2006 Research Monthly, RiskMetrics Group, New York, United States.

[25] FINGER, C., (2009), IRC Comments, RiskMetrics Broup Research Monthly, February, New York, United States.

[26] FINANCIAL SERVICES AUTHORITY, (2009), The Turner Review: A regulatory response to the global banking crisis, Publication Reference 003289, The Financial Services Authority, London, United Kingdom, available at: http://www.fsa.gov.uk. (Accessed October 2009).

[27] FTSE RUSSELL, (2015), Guide to Calculation Methods for the FTSE UK Index Series v. 5.3, October 2015, London, United Kingdom.

[28] Gobbo, F., (2020), Implications on banks' risk management: 6 areas risk leaders can help their organizations now and in the post-COVID 'new reality', KPMG Italy, Italy. Available at:

[29] https://home.kpmg/xx/en/blogs/home/posts/2020/05/implications-on-risk-management.html

[30] Jackson, P., (2016), The likely path for Basel Capital Requirements - piecemeal change rather than Basel IV?, Global Regulatory Network Executive Briefing, Ernst \& Young Global Limited, London, United Kingdom.

[31] JP MORGAN and REUTERS, (1996), RiskMetrics Technical Document, Fourth Edition, New York, United States.

[32] KPMG, (2016), The world awaits: Basel 4 nears completion, KPMG International, Amstelveen, Netherlands. Available at:

https://assets.kpmg/content/dam/kpmg/xx/pdf/2016/12/world-awaits-basel-4-nearscompletion.pdf 
[33] Magnus, M., Duvillet-Margerit, A., and Mesnard, B., (2017), Upgrading the Basel Standards: from Basel III to Basel IV?, Directorate-General for Internal Policies, Economic Governance Support Unit, European Parliament, Brussels, Belgium.

[34] Manganelli, S., and Engle, R. F., (2001), Value at Risk Models in Finance, Working Paper No.75, European Central Bank Working Paper Series, Frankfurt, Germany.

[35] Markowitz, H., (1952), Portfolio Selection, Journal of Finance, Vol. 7, pp. 77-91.

[36] McNEIL, A. J., FREY, R., EMBRECHTS, P., (2005), Quantitative Risk Management: Concepts, Techniques and Tools, Princeton University Press, Princeton, New Jersey, United States.

[37] Mcsheaffrey, P., JENKINS, T., MONTElORTE, M., GERVACIO, M., KANG, C., CHAN, C., ER, G. and PHILPOTT, J., (2020), Financial risk management for banks: Responding to the challenges presented by Covid-19. Covid-19 implications for credit, market, operational and liquidity risks, KPMG, Honk Kong. Available at: https://assets.kpmg/content/dam/kpmg/cn/pdf/en/2020/04/financial-riskmanagement-for-banks-responding-to-challenges-presented-by-covid-19.pdf

[38] Merle, R., (2020), Big banks want regulation eased because of coronavirus. Experts call it opportunistic, Washington Post, published on March 3, 2020. Available at: https://www.washingtonpost.com/business/2020/03/03/banks-lobby-coronavirus/

[39] Nelson, D. B., (1991), Conditional Heteroskedasticity in Asset Returns: A New Approach, Econometrica, Vol. 59, pp. 347-370. https://doi.org/10.2307/2938260

[40] Reiss, R.-D., and M. Thomas, (2007), Statistical Analysis of Extreme Values with Applications to Insurance, Finance, Hydrology and Other Fields, Birkhäuser Verlag, AG, Berlin, Germany.

[41] Rossignolo, A. F., Fethi, M. D., and Shaban, M., (2013), Market crises and Basel Capital Requirements. Could Basel III have been different? Evidence from Portugal, Ireland, Greece and Spain (PIGS), Journal of Banking and Finance,Volume 37, Issue 5, pp. 1323-1339. https://doi.org/10.1016/j.jbankfin.2012.08.021

[42] Rossignolo, A. F., Fethi, M. D and Shaban, M., (2012), Value-at-Risk Models and Basel Capital Charges, Journal of Financial Stability, Volume 8, Issue 4, pp. 303-319. https://doi.org/10.1016/j.jfs.2011.11.003

[43] Schneider, S., Schröck, G., Koch, S., and Schneider, R., (2017), Basel "IV": What's next for banks?. Implications of intermediate results of new regulatory rules for European banks, Global Risk Practice April 2017, Berlin, Germany. Available at: https://www.mckinsey.com/ /media/mckinsey/business\%20functions/risk/our\%20insights/base 1\%20iv\%20whats\%20next\%20for\%20european\%20banks/basel-iv-whats-next-for-banks.ashx

[44] Taleb, N. N., (2007), The Black Swan: The Impact of the Highly Improbable, Random House, New York, United States.

[45] Van der GOORBERGH, R. W. J. and P. J. G. VLAAR, (1999), Value-at-Risk Analysis of Stock Returns: Historical Simulation, Variance Techniques or Tail Index Estimation?, WO Research Memoranda No. 579, Netherlands Central Bank Research Department, Amsterdam, Netherlands.

[46] Wallace, P., (2017), Regulate thy neighbour, Financial World, February/March 2017, The London Institute of Banking and Finance in association with CSFI (Centre for the Study of Financial Innovation), London, United Kingdom, pp. 30-31.

[47] WORLD FEDERATION OF STOCK EXCHANGES, (2015), Monthly reports, 31 January 2015, Paris, France. 